\title{
Reflexiones en torno a la inmunidad de jurisdicción penal de los Jefes de Estados ante la comisión de crímenes internacionales en el marco del Estatuto de Roma
}

\author{
Reflections regarding the immunity of criminal jurisdiction \\ of the Heads of States before the Commission of International \\ Crimes in the framework of the Rome Statute
}

\author{
Juan Bautista CARTES RODRÍGUEZ \\ Universidad Complutense de Madrid \\ jcartes@ucm.es
}

RECIBIDO EL 15 DE ENERO DE 2019 / ACEPTADO EL 13 DE FEBRERO DE 2019

Resumen: El presente artículo pretende abordar algunas cuestiones que se han venido planteado relativas a la inmunidad de jurisdicción penal de los Jefes de Estado en ejercicio de sus funciones ante la Corte Penal Internacional (CPI). Partiendo de la distinción entre dos planos - aunque correlacionados- distintitos, como son, por una parte, la relación vis-à-vis entre la CPI y el Estado del agente y, por otra, la relación triangular entre la Corte, el Estado requerido y el Estado del agente, el autor pone de manifiesto la incoherente y voluble línea jurisprudencial adoptada por la CPI y apoya las tesis que defienden la existencia de una excepción de Derecho consuetudinario respecto a la inmunidad de jurisdicción penal de los Jefes de Estado cuando estos son acusados de cometer crímenes internacionales que alcanza al primer plano planteado, pero no así al segundo.

Palabras clave: inmunidad de jurisdicción penal; Jefes de Estado; Corte Penal Internacional; Al Bashir.

\begin{abstract}
This article aims to address some questions surrounding the topic of the immunity of criminal jurisdiction of Heads of State in the exercise of their functions before the International Criminal Court (ICC). In the first place, the author starts from the distinction between two -although correlated - different planes, such as, on the one hand, the vis-à-vis relationship between the ICC and the State of the agent and, on the other hand, the triangular relationship between the Court, the requested State and the State of the agent. Taking into account such a distintion, the author highlights the incoherent jurisprudential line adopted by the ICC and supports the thesis that defends the existence of an exception of customary law with respect to the immunity of criminal jurisdiction of the Heads of State when the subject is accused of committing international crimes that are related to the first type of plane mentioned above but not the second one.
\end{abstract}

Keywords: immunity from criminal jurisdiction; Heads of State; International Criminal Court; Al Bashir.

Sumario: 1. INTRODUCCIÓN. 2. APROXIMACIÓN AL DERECHO INTERNACIONAL VIGENTE. 2.1. La problemática de la inmunidad ratio materiae y ratio personae de los Jefes de Estado ante la comisión de crímenes internacionales en el plano nacional e internacional, en general... A) Ante tribunales nacionales extranjeros. B) Ante tribunales internacionales. 2.2. ...Y en particular en el Estatuto de Roma: hacia la conciliación de la lectura conjunta de los artículos 27 y 98.1. 3. ACTUACIONES DE LA CPI SOBRE JEFES DE ESTADO AFRICANOS: PLASMACIÓN PRÁCTICA DE LA DISYUNTIVA TEÓRICA EN TORNO AL JUEGO DE LA INMUNIDAD EN EL ESTATUTO DE ROMA. 3.1. El caso Al Bashir. A) Relación vis-á-vis de la Corte con el Estado de Sudán. B) Relación triangular entre la Corte, el Estado requerido y el Estado de Sudán a) La vía del Derecho consuetudinario. b) La vía del Consejo de Seguridad. 3.2. Caso Gadafi. 3.3. Caso Kenyatta. 3.4. Caso Gbagbo. 4. CONCLUSIONES 


\section{INTRODUCCIÓN}

A dentrarnos en la problemática de los límites y excepciones de la inmunidad de jurisdicción penal de los funcionarios y agentes del Estado supone indagar en uno de los elementos centrales y más controvertidos del desarrollo del Derecho internacional vigente. Como muestra de ello, en los últimos años la Corte Internacional de Justicia (CIJ) se ha pronunciado hasta en dos ocasiones sobre la cuestión de la inmunidad, una de ellas directamente sobre el tema que nos ocupa ${ }^{1}$, y recientemente el Instituto de Derecho Internacional (IDI) ha adoptado distintas resoluciones sobre dicha materia ${ }^{2}$. Asimismo, desde 2007 la Comisión de Derecho Internacional (CDI) viene incluyendo en su programa de trabajo la cuestión relativa a la inmunidad de jurisdicción penal extranjera de los funcionarios del Estado.

La intrincada naturaleza de esta materia deviene de la contraposición entre dos extremos representativos del Derecho internacional vigente: por un lado, el proceso de humanización que nuestro ordenamiento jurídico viene experimentando en las últimas décadas -materializado en la responsabilidad penal internacional del individuo ante la comisión de crímenes internacionales- $\mathrm{y}$, por otro, la pervivencia del clásico principio de igualdad soberana de los Estados -concretado, en este caso, en el respeto de las inmunidades de los más altos cargos estatales-.

Ante este complejo marco, el presente artículo se centrará en las actuaciones de la Corte Penal Internacional (CPI) ante los crímenes internacionales cometidos por Jefes de Estado, principalmente africanos, donde la

1 Asunto relativo a la orden de arresto de 11 de abril de 2000 (República Democrática del Congo c. Bélgica), Sentencia de 14 de febrero de 2002, C.I.7. Recueil 2002, en adelante Asunto Arrest Warrat; Asunto Inmunidades jurisdiccionales del Estado (Alemania c. Italia; Grecia interviniente), Sentencia de 3 de febrero de 2012, C.I.7. Recueil 2012. Mientras que la primera Sentencia versa sobre la inmunidad de jurisdicción penal extranjera de los funcionarios del Estado -concretamente del Ministro de Relaciones Exteriores-, la segunda se centra en la inmunidad del Estado en sentido estricto. Citando a Concepción Escobar Hernández, C., ILC, «Fifth report on immunity of State officials from foreign criminal jurisdiction», Anuario de la Comisión de Derecho Internacional, vol. II, Geneva, 2016, p. 73. Doc. A/CN.4/701, «un mismo acto puede generar dos tipos distintos de responsabilidad: del Estado y del individuo y la existencia de dos tipos de responsabilidad se traduce en dos tipos de inmunidad (del Estado y de su funcionario)».

2 Vid. infra nota 15. 
dicotomía antes mencionada se ha evidenciado con una viveza significativa. Así pues, en el presente escrito abordamos si en el Derecho vigente existe una excepción consuetudinaria al principio de inmunidad de jurisdicción penal de los Jefes de Estado cuando estos estén acusados de la comisión de crímenes internacionales y sean juzgados e investigados ante tribunales internacionales. Procediendo a dilucidar en el caso concreto de la Corte Penal Internacional, definida como «a giant without limbs» ${ }^{3}$, si en la cooperación y asistencia judicial de los Estados con la CPI, que origina una relación triangular entre la Corte, el Estado requerido y el Estado del agente, también rige el principio de improcedencia del cargo oficial con independencia de que el Estado requerido y el del agente sean o no Estados parte en el Estatuto de Roma y con independencia de que la jurisdicción de la Corte sea resultado de una remisión del CSNU en virtud del capítulo VII de la Carta de NNUU.

Para adentrarnos en el objeto de estudio planteado, el segundo epígrafe del presente artículo se presenta como una aproximación al Derecho internacional vigente, distinguiendo entre la inmunidad ratio materiae y ratio personae de los Jefes de Estado, tanto ante tribunales nacionales como internacionales, cuando estos son acusados de cometer o instigar la comisión de crímenes internacionales. Ello nos servirá de preludio para, a continuación, detenernos en el principio de improcedencia del cargo oficial consagrado en el Estatuto de Roma y en la difícil lectura conjunta de sus artículos 27 y 98.1.

Por su parte, en el tercer epígrafe se analizarán los distintos pronunciamientos de la Corte Penal Internacional relativos a la inmunidad de jurisdicción penal de los Jefes de Estados, con especial atención al caso Al Bashir, pues es en este asunto donde la Corte se ha pronunciado con un mayor detalle sobre dicha cuestión. Si bien avanzamos que la CPI, en ocasiones, ha confundido los distintos planos mencionados y ha virado en el fundamento jurídico de las decisiones adoptadas -unas veces acudiendo a la costumbre internacional y otras al carácter obligatorio de las remisiones del CSNU-, hecho que no ha contribuido a establecer una jurisprudencia uniforme al respecto. Para acabar, finalizaremos con la exposición de una serie de conclusiones sobre lo abordado en el presente artículo.

3 Maogoto, J. N. «A Giant Without Limbs: The International Criminal Court's State-Centric Cooperation Regime», Social Science Research Network, June 2004, pp. 1-51. 


\section{APROXIMACIÓN AL DERECHO INTERNACIONAL VIGENTE}

\subsection{La problemática de la inmunidad ratio materiae $y$ ratio personae de los fefes de Estado ante la comisión de crímenes internacionales en el plano nacional e internacional, en general...}

El Jefe de Estado, junto con el Presidente de Gobierno y el Ministro de Asuntos Exteriores, constituyen los órganos centrales del Estado con competencia en materia de acción exterior ${ }^{4}$. De manera que, para garantizar el principio de igualdad soberana de los Estados, facilitar el mantenimiento de relaciones internacionales estables y permitirles el desempeño adecuado de las funciones que les son propias, éstos cuentan con una serie de privilegios e inmunidades que se encuentran contenidos exclusivamente en normas consuetudinarias ${ }^{5}$.

Entre las referidas prerrogativas, se halla la inmunidad de jurisdicción penal extranjera, la cual ha sido definida como «the protection from the exercise of criminal jurisdiction by the judges and courts of another State that is enjoyed by certain State officials ${ }^{6}$.

Por consiguiente, la referida inmunidad se erige como un principio de carácter procesal, que actuando como excepción, da lugar a la incompetencia

4 Vid. López Martín, A. G., «Las inmunidades del Derecho internacional: su aplicación en España», Cuadernos de Derecho Público, n. ${ }^{\circ} 6,1999$, p. 168. No serán objeto de estudio las inmunidades de órganos específicos de la Administración exterior del Estado entre los que se encuentran las misiones diplomáticas, las misiones especiales, las representaciones permanentes ante Organizaciones o Conferencias Internacionales y las oficinas consulares.

5 Vid. Díaz de Velasco, M., «Instituciones de Derecho Internacional Público», $18^{a}$ ed., Madrid, Tecnos, 2013, p. 399. En el DI convencional vigente tan sólo se hace una referencia genérica a las mismas en el art. 21 de la Convención sobre misiones especiales de 16 de diciembre de 1969. Debiendo señalarse que actualmente la CDI se encuentra elaborando un proyecto de artículos sobre la inmunidad de jurisdicción penal extranjera de los funcionarios del Estado. Vid. ILC, «Report on the work of the sixty-eighth session», Anuario de la CDI, vol. II, 2016, p. 80 y ss. Doc. A/71/10.

6 ILC, «Second report on the immunity of State officials from foreign criminal jurisdiction», Anuario de la CDI, vol. II, Geneva, 2013, p. 17. Doc. A/CN.4/661.

En palabras de Carnerero CaStiLla, R., «La inmunidad de jurisdicción penal de los fefes de Estado extranjeros», $1^{\text {a }}$ ed., Madrid, Iustel, 2007, p. 32. «la inmunidad conlleva la ausencia del poder que habitualmente les corresponde a las autoridades del Estado territorial o, al menos, la obligación de abstenerse de ejercerlo. Mientras que, de las varias acepciones reconocidas al vocablo jurisdicción en la terminología jurídica, su utilización en la expresión «inmunidad de jurisdicción» alude a la más tradicional de ellas, considerándose como sinónimo de competencia; de modo que, cuando se aplica a un tribunal, se refiere principalmente a la competencia judicial, es decir, a su poder $-\mathrm{o}$ falta de poder- para resolver controversias jurídicas por medios pacíficos». 
de los tribunales para el enjuiciamiento de un individuo concreto ${ }^{7}$. Ahora bien, el objeto de estudio de esta obra nos lleva a preguntarnos si la inmunidad de jurisdicción penal de la que gozan los Jefes de Estado opera y, en su caso, con qué alcance, cuando el acto realizado tiene la consideración de crimen internacional ${ }^{8}$.

Para aproximarnos acertadamente a esta cuestión ha de tenerse en cuenta, de manera previa, dos clasificaciones que se complementan. En primer lugar, frente a la jurisdicción extranjera, el Derecho internacional reconoce dos tipos de inmunidades: la inmunidad personal -también llamada ratio personae- y la inmunidad funcional -también llamada ratio materiae-. La inmunidad ratio materiae cubre los actos realizados por los agentes estatales a título oficial y en nombre del Estado que se representa, no estando sometida a límite temporal alguno pues subsiste después de cesar del cargo?.

$7 \quad$ Ibid., p. 32.

8 A este respecto, como establece el «Quinto informe sobre la inmunidad de jurisdicción penal extranjera de los funcionarios del Estado», presentado por la Relatora Especial, EsCOBAR HernándeZ, C., Doc. A/CN.4/70, Anuario de la CDI, vol. II, Ginebra, 2016., pp. 97-98; la definición de un límite o excepción a la inmunidad de jurisdicción penal extranjera exige que se precise de manera previa dos ámbitos: (1) la delimitación del concepto de crimen internacional y (2) la identificación de los comportamientos delictivos que, incluyéndose en dicha categoría, excepcionan la inmunidad de jurisdicción penal. Respecto del primero, a tal efecto, se entiende por crimen internacional aquellos comportamientos delictivos «que atañen a valores jurídicos internacionales con independencia del lugar en que se puedan cometer los mismos». Mayor controversia existe en relación a la segunda cuestión. Siguiendo con el planteamiento de la Relatora Especial, «en realidad, analizando dicha práctica, cabe concluir que los crímenes internacionales que sirven de base para limitar o exceptuar la aplicación de la inmunidad son aquellos respecto de los cuales existe un amplio consenso en la comunidad internacional para considerarlos como crímenes que pueden ser objeto de persecución penal por parte de los tribunales penales internacionales y, en especial, la Corte Penal Internacional. En consecuencia, los crímenes en cuestión deben identificarse con los crímenes de genocidio, lesa humanidad y crímenes de guerra». Esta es la posición mantenida, entre otros, por REMIRO BROTÓNS, A., Derecho Internacional, Valencia, Tirant lo Blanch, 2007, p. 493, quien establece que son tales crímenes aquellos que han sido prohibidos por normas de ius cogens. En cambio, otros autores como Bassiouni, M., Crimes against Humanity: Historical Evolution and Contemporary Application, Cambridge, Cambridge University Press, 2011, p. 174, abogan por incluir, junto a los mencionados, la tortura y las infracciones graves a los cuatro Convenios de Ginebra de 1949.

Sobre la complejidad de tal cuestión también se ha pronunciado CHINCHÓN ÁLVAREZ, J., Derecho internacional y transiciones a la democracia y la paz: Hacia un modelo para el castigo de los crímenes pasados a través de la experiencia iberoamericana, Madrid, Parthenon, 2007, p. 176 y ss.

En cualquier caso, ha de tenerse presente que al referirnos en esta obra a la expresión «crímenes internacionales», no estamos aludiendo a cualquier comportamiento delictivo que atañen a valores jurídicos internacionales con independencia del lugar en que se puedan cometer los mismos, sino solo a algunos de ellos, siguiendo la noción más restringida a la que se ha hecho referencia.

9 Para un análisis detallado de dicho concepto, vid. supra, nota 7, p. 17. 
Por su parte, la inmunidad ratio personae se extiende a los actos tanto públicos como privados realizados durante el mandato o con anterioridad al mismo de una categoría reducida de agentes estatales y tiene un carácter temporal, en tanto que cesa una vez que se deja de desempeñar el cargo ${ }^{10}$.

En segundo lugar, la inmunidad de jurisdicción penal de los Jefes de Estado ante tribunales nacionales de terceros Estados no puede ser equiparada, como tendremos ocasión de exponer, con la inmunidad de jurisdicción penal ante tribunales internacionales.

Así pues, el Derecho internacional vigente impone armonizar ambas clasificaciones, incorporando el concepto de inmunidad ratio materiae y ratio personae tanto respecto de los tribunales nacionales extranjeros como respecto de los tribunales penales internacionales.

\section{A) Ante tribunales nacionales extranjeros}

Comenzando por la inmunidad personal ante tribunales nacionales extranjeros, si bien ésta es absoluta en relación a los delitos ordinarios, surge la pregunta de su alcance en relación a crímenes internacionales. Atendiendo a los pronunciamientos judiciales ${ }^{11} \mathrm{y}$ doctrinales ${ }^{12}$ la inmunidad personal de los Jefes de Estado ante tribunales nacionales extranjeros no ha sido objeto de excepción, con independencia del delito cometido, desde la finalización de la Segunda Guerra Mundial.

Igualmente, es ésta la posición mantenida por la $\mathrm{CDI}^{13}$, el $\mathrm{IDI}^{14}$, así como por la CIJ en el asunto Arrest Warrant, donde la Corte mantuvo que «no se puede deducir del derecho internacional consuetudinario una excepción cualquiera a la regla que consagra la inmunidad de jurisdicción penal de los ministros de asuntos exteriores en ejercicio [y, por analogía, de los Jefes de Estado o de Gobierno], cuando son acusados de haber cometido crímenes de guerra o de lesa humanidad $\gg^{15}$.

10 Ibidem.

11 Así lo prueba el archivo de los casos contra Eric Honecker, Hassan II, Fidel Castro, Muammar Gaddafi y Paul Kagame, entre otros, por parte de tribunales de estados europeos, todos ellos Jefes de Estado en ejercicio en el momento de la apertura de las actuaciones judiciales.

12 Entre otros, vid. Carnerero Castilla, «La Inmunidad...», op. cit., p. 62 y ss.

13 Vid. ILC, «Fifth report...», op. cit., párr. 237.

14 Vid. Resolución de 2001 adoptada en Vancouver y Res. 2009 adoptada en Nápoles (arts. 13 y II respectivamente).

15 Vid. supra, nota 1., párr. 58. En dicho Asunto la República Democrática del Congo demandó al Reino de Bélgica ante la CIJ por haber violado la normativa internacional en materia de 
Más controvertida deviene la cuestión en relación a la inmunidad funcional, pues tanto la doctrina como la jurisprudencia divergen a este respecto. Uno de los pronunciamientos menos dubitativos ha sido el mantenido por el IDI al establecer en su resolución de 2009 que «aparte de la inmunidad personal de la que se benefician los agentes estatales en virtud del Derecho internacional, ninguna inmunidad se aplica al caso de crímenes internacionales» ${ }^{16}$.

Por contra, si bien distintos tribunales nacionales han rechazado que los agentes estatales puedan alegar su inmunidad funcional ante la comisión de crímenes internacionales - tal es el caso de Fortunato Galtieri en España, Desi Bouterse en los Países Bajos, Abdusalami Abubakar en EEUU, Hashemi Rafsanjani en Argentina o Pinochet en España y Reino Unido-, hasta la actualidad, ninguna condena penal ha sido impuesta a un ex Jefe de Estado por tribunales nacionales extranjeros. En el asunto Arrest Warrant la CIJ también se ha mostrado reticente en relación a este planteamiento, pues, al señalar los actos que, siendo realizados durante el ejercicio del cargo, no se benefician de la inmunidad de jurisdicción penal una vez terminado el mismo, únicamente se ha referido a aquellos realizados a título privado, en contraposición de aquellos actos de carácter oficial, los cuales, según establece la Corte, siguen estando cubiertos por la inmunidad ${ }^{17}$.

A este respecto, una parte de la doctrina sostiene que la CIJ implícitamente reconoce en dicho pronunciamiento la excepción a la inmunidad

inmunidad de los agentes estatales en tanto que el juez de instrucción del Tribunal de primera instancia de Bruselas, Damien Vandermeersch, dictó en abril de 2000 una orden de arresto contra Yerodia Ndombasi, entonces Ministro de Asuntos Exteriores, siendo acusado de cometer crímenes internacionales contra la etnia tutsi. Para un análisis detallado de dicho pronunciamiento, vid. Carnero Castilla, R., «Un paso atrás en la lucha contra la impunidad. La sentencia de la Corte Internacional de Justicia de 14 de febrero de 2002 en el «Asunto relativo a la orden de arresto de 11 de abril de 2000» (República Democrática del Congo c. Bélgica)», en Sánchez Rodríguez, L. I. (ed.), El poder de los jueces y el estado actual del derecho internacional: análisis crítico de la jurisprudencia internacional (2000-2007), Universidad del País Vasco, 2010, pp. 125-142.

16 En una línea similar se pronuncia la Ley Orgánica 16/2015, de 27 de octubre, al establecer en su art. 23.1 que «una vez finalizado su mandato, los antiguos Jefes de Estado y de Gobierno y los antiguos Ministros de Asuntos Exteriores continuarán disfrutando de inmunidad penal únicamente en relación con los actos realizados durante su mandato en el ejercicio de sus funciones oficiales, con el alcance que determina el Derecho internacional [si bien] quedarán excluidos de la inmunidad los crímenes de genocidio, desaparición forzada, guerra y lesa humanidad». Igualmente, Escobar HernáNDEZ, C., ILC, «Fifth report...», op. cit., párr. 121, señala la existencia de una «tendencia mayoritaria» que excepciona la inmunidad ratione materiae ante la comisión de crímenes internacionales. No obstante, la Relatora Especial reconoce que los argumentos alegados para mantener tal excepción no son uniformes.

17 Ibid., párr. 61. 
funcional, pues los actos que constituyen crímenes internacionales en modo alguno pueden ser considerados actos realizados por los agentes estatales a título oficial ${ }^{18}$. Esta posición ha sido también mantenida por algunos de los jueces de la CIJ que en el caso Arrest Warrant emitieron votos particulares, al igual que por determinados magistrados de la Cámara de los Lores en el asunto Pinochet ${ }^{19}$. Sin embargo, como establece Akande «whether or not acts of state officials are regarded as official acts does not depend on the legality, in international or domestic law, of those acts. Rather, whether or not the acts of individuals are to be deemed official depends on the purposes for which the acts were done and the means through which the official carried them out $\gg^{20}$. Más aún, de mantenerse que todos los crímenes internacionales han de considerarse como actos privados «tampoco podría atribuirse éstos al Estado en cuyo nombre actuaron los agentes estatales, y, en consecuencia, el Estado no sería responsable, ni tendría que proceder a la reparación de las víctimas $\gg^{21}$.

Ante este razonamiento, algunos autores han señalado que al ser considerada la prohibición de cometer crímenes internacionales o, al menos algunos de ellos, una norma de ius cogens, ésta debe prevalecer desde un plano normativo sobre aquellas que tienen un rango inferior, cual es la norma consuetudinaria relativa a la inmunidad funcional ${ }^{22}$. No obstante, autores como Sáenz de Santamaría ${ }^{23}$, H. Fox ${ }^{24}$ y D. Akande ${ }^{25}$, sostienen que mientras las primeras operan en un plano sustantivo, las segundas operan en un plano procesal, por lo que «la norma sobre inmunidad funcional no contradice ninguna prohibición contenida en las normas de ius cogens, sino que se limita a remitir sus

18 Entre otros autores que mantienen dicha posición, vid. BIANCHI, A., «Immunity Versus Human Rights: The Pinochet Case», European Fournal of International Law, vol. 10, n. ${ }^{2}$, pp. 237-277.

19 A este respecto se pronunció Lord Nicholls of Birkenhead y Lord Steyn. Vid. Regina v. Bartle and the Commissioner of Police for the Metroplolis and others, Ex Parte Pincochet, Cámara de los Lores de Inglaterra, Sentencia de 24 de marzo de 1999, International Legal Materials, vol. 38, n. ${ }^{\circ}$, 1999, pp. 113-116.

20 Akande, D., «Immunities of State Officials, International Crimes, and Foreign Domestic Courts», European Fournal of International Law, vol. 22, n. ${ }^{\circ}$ 4, 2011, p. 832.

21 Vid. Амвоs, K., «Treatise on International Criminal Law», Oxford University Press, Reino Unido, 2013 , p. 412.

22 Vid. Remiro Brotóns, A., «El Caso Pinochet. Los límites de la inmunidad», Madrid, Política Exterior, Biblioteca Nueva, 1999. p. 115.

23 Vid. Andrés SÁEnz de Santamaría, P., «Sistema de Derecho Internacional Público», $4^{\mathrm{a}}$ ed., Pamplona, Civitas, 2016, pp. 85 y ss.

24 Vid. Fox, H., «The Law of State Immunity», $3^{\text {a }}$ ed., Reino Unido, Oxford University Press, 2004, p. 525 .

25 AKANDE, D., «Immunities of...», op. cit., p. 828. 
infracciones a un mecanismo distinto de resolución de controversias». Esta la línea argumental ha sido confirmada por la CIJ en el asunto Arrest Warrant ${ }^{26}$.

Así las cosas, podemos afirmar que pese a la existencia de pronunciamientos judiciales nacionales que no han reconocido la inmunidad funcional ante crímenes internacionales cometidos por ex Jefes de Estado, posición a la que se une un sector doctrinal, la cuestión en el Derecho internacional vigente está lejos de ser pacífica.

B) Ante tribunales internacionales

Los argumentos que justifican la inmunidad de jurisdicción penal de los altos cargos estatales ante tribunales nacionales extranjeros no rigen para los tribunales internacionales, en tanto que al operar desde una perspectiva vertical y no horizontal no ha de preservarse el principio de igualdad soberana de los Estados y, por ende, el principio «par in parem non habet imperium» no resulta de aplicación, razón por la cual, existe consenso en afirmar que la inmunidad ante una jurisdicción penal internacional es sustancialmente diferente respecto de la inmunidad ante una jurisdicción penal nacional ${ }^{27}$.

Esta dualidad comienza a evidenciarse tras el final de la Primera Guerra Mundial, siendo concebido el artículo 227 del Tratado de Versalles para enjuiciar al emperador alemán, Guillermo II, «por actos contra la moralidad internacional y la autoridad sagrada de los tratados». Si bien el Káiser finalmente no fue juzgado, el rechazo a las inmunidad de los Jefes de Estado volvería a plantearse en el Estatuto del Tribunal Militar Internacional de Nuremberg, en cuyo artículo 7 se dispuso que «el cargo oficial de los acusados, ya sean Jefes de Estado o funcionarios a cargo de Departamentos del Gobierno no les exonerará de las responsabilidades ni servirá para atenuar la pena». Similar disposición fue establecida en el artículo 6 del Estatuto del Tribunal Militar Internacional para el Lejano Oriente ${ }^{28}$. A partir de entonces, la restricción de las inmunidades de los altos cargos del Estado cristalizará en distintos documentos como la Convención para la Prevención y la Sanción del Delito

26 Supra nota 1, párr. 60. Confirmar el número definitivo de la nota.

27 Vid. Abrisketa URIarTe, J., «Al Bashir: ¿Excepción a la inmunidad del Jefe de Estado de Sudán y Cooperación con la Corte Penal Internacional?», Revista Española de Derecho Internacional, vol. 68, n. ${ }^{\circ} 1,2016$, p. 20.

28 No obstante, tales Tribunales han sido objeto de determinadas críticas, siendo calificados como «jurisdicciones creadas por los vencedores del conflicto para juzgar los crímenes de las potencias vencidas». Vid. CHINCHÓN ÁlvareZ, J., «Derecho...», op. cit., p. 94. 
de Genocidio (1948), los Principios de Nuremberg (1950) y el Proyecto de Código de Crímenes contra la Paz y la Seguridad de la Humanidad (1996).

Asimismo, en el contexto de posguerra fría, el Consejo de Seguridad de la ONU constituyó los tribunales penales ad hoc para la Antigua Yugoslavia (1993) y Ruanda (1994) con objeto de juzgar las atrocidades que se cometieron en dichos territorios, disponiéndose en sus respectivos Estatutos que «la categoría oficial de un acusado, ya sea como Jefe de Estado o de Gobierno, o como alto funcionario, no le exonera de su responsabilidad penal y no es motivo de disminución de la pena». Misma disposición se encuentra en el Estatuto del Tribunal Especial para Sierra Leona, instituido mediante acuerdo entre la ONU y el Gobierno de Sierra Leona.

Estos antecedentes, en parte corolario del proceso de humanización que en las últimas décadas viene produciéndose en el Derecho internacional, favorecieron la creación de una Corte Penal Internacional permanente que, instituida sobre el principio de complementariedad respecto a las jurisdicciones penales nacionales (art. 1), tiene competencia sobre cualquier persona acusada de cometer crímenes de guerra, genocidio, crímenes de lesa humanidad y agresión (art. 5) bien en el territorio de un Estado parte, bien en el territorio de un Estado tercero que haya aceptado la competencia de la misma (art. 12) ${ }^{29}$, evitando que dichos crímenes internacionales que atentan contra toda la humanidad queden impunes.

Igualmente, en el asunto Arrest Warrant, donde la CIJ mantiene una posición proteccionista respecto a la inmunidad de jurisdicción penal de los altos cargos estatales, al referirse a los supuestos en los que dicho procesamiento no se vería impedido, sostuvo que:

«Un Ministro de Asuntos Exteriores [y por analogía, un Jefes de Estado o de Gobierno], que se encuentre ejerciendo su cargo o lo haya ejercido, puede ser sometido a actuaciones penales ante ciertos tribunales internacionales, cuando éstos tengan competencia. Como ejemplos se puede citar el Tribunal Penal Internacional para la antigua Yugoslavia y el Tribunal Penal Internacional para Ruanda [...] así como la futura Corte Penal Internacional» ${ }^{30}$.

29 Art. 12 Estatuto de Roma. En igual situación se encontraría, si el crimen se hubiere cometido a bordo de un buque o de una aeronave, el Estado de matrícula del buque o la aeronave que fuera Parte en el Estatuto o que hubiera aceptado la competencia de la Corte. Art. 12.2 (a) ER.

30 Supra nota 1, párr. 61. Junto a la referida, existen otras tres vías que posibilitan tal enjuiciamiento: «en sus propios Estados, cuando así se lo permita su legislación; cuando se les retire esa inmunidad; y cuando cesen en el cargo, pero solo respecto de las actividades realizadas en la esfera privada». Vid. Gutiérrez Espada, C.; Cervell Hortal, M. J., «Darfur, el conflicto inacabable», Pamplona, Thomson Reuters Aranzadi, 2012, p. 179. 
Teniendo en cuenta lo planteado hasta ahora, surge la pregunta de si existe una excepción consuetudinaria al principio de inmunidad de jurisdicción penal de los Jefes de Estado ante tribunales internacionales o si, por el contrario, nos encontramos ante una norma autónoma de carácter sustantivo ${ }^{31}$. Asimismo, habrá que responder si ésta se extiende tanto a la inmunidad ratio materiae como la inmunidad ratio personae o únicamente atañe a la primera. Respondiendo a la cuestión inicial, como ha sido señalado por Ambos, «existe una alto grado de consenso entre la doctrina y la jurisprudencia de los distintos tribunales internacionales sobre su naturaleza de excepción consuetudinaria a la regla de inmunidad $»^{32}$.

Respecto de la segunda cuestión, compartimos la postura de autores como C. Kreß ${ }^{33}$, P. Gaeta ${ }^{34}$, A. Casesse ${ }^{35}$, M. Diaz de Velasco ${ }^{36}$, C. Escobar Hernández $^{37}$, R. Carnerero Castilla ${ }^{38}$ y M. J. Cervell Hortal ${ }^{39}$ al establecer que la excepción consuetudinaria al principio de inmunidad de los Jefes de Estado ante tribunales internacionales por la comisión de crímenes internacionales no solo afecta a la inmunidad funcional sino también a la personal ${ }^{40}$. Así pues, junto a los principios enunciados que se han ido paulatinamente consolidando desde el final de la Primera Guerra Mundial, también existe una práctica de

31 Vid. Olasolo Alonso, H. et al., «La Inmunidad de Jurisdicción Penal por Crímenes Internacionales de los Jefes de Estado, los Jefes de Gobierno y los Ministros de Asuntos Exteriores», Revista Chilena de Derecho, vol. 43, n. ${ }^{\circ}$ 1, 2016, p. 271.

32 Vid. Амвоs, K., «Treatise on International Criminal Law», Oxford University Reino Unido, Press, 2013, p. 415, en H. Olasolo Alonso et al., «La Inmunidad...», op. cit., p. 271.

33 Vid. KRess, C., «Las inmunidades de Derecho internacional para los Estados no parte en el Estatuto de la Corte Penal Internacional» Revista General de Derecho Penal, n. ${ }^{\circ}$ 19, 2013, p. 29.

34 Vid. Gaeta, P., «Official capacity and immunities», en The Rome Statute of the International Criminal Court: a commentary, Oxford University Press, Oxford, 2002, p. 996.

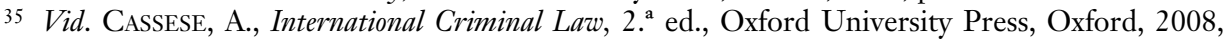
p. 312.

36 Vid. Díaz de Velasco, M., «Instituciones...», op. cit., p. 402.

37 Vid. ILC, «Fifth report...», op. cit., párr. 50.

38 Vid. Carnerero Castilla, R., «La Inmunidad...», op. cit., p. 224.

39 Vid. Cervvell Hortal, M. J., «La resolución 1970 (2011) del Consejo de Seguridad y la remisión de la cuestión libia a la CPI: ¿la unión hace la fuerza?» Anuario Español de Derecho Internacional, vol. 27, 2011, p. 87.

40 En contra de la existencia de tal excepción consuetudinaria se pronuncia AKANDE, D., «International Law Immunities and the International Criminal Court», American fournal of International Law, vol. 98, n. ${ }^{\circ} 3,2004$, p. 418,

Por su parte, la Unión Africana mantiene la existencia de una excepción al principio de inmunidad de jurisdicción penal de los Jefes de Estado cuando éstos sean enjuiciados por tribunales internacionales una vez que cesan en el cargo. Por tanto, según la UA tal excepción solo quedaría referida a la inmunidad ratio materiae. Vid. Capítulo III, Sec. 3. 
los tribunales internacionales basada en una obligación jurídica constitutiva de opinio iuris.

Tal es el caso de la jurisprudencia mantenida por el TPIY en los asuntos Furundzija, Karadzic y Milosevic -éste último Presidente de la República Federativa de Yugoslavia en el momento de iniciarse las actuaciones penales- al establecer que:

«Individuals are personally responsible, whatever their official position, even if they are Heads of State or government ministers: Article 7(2) of the Statute and article 6(2) of the Statute of the International Criminal Tribunal for Ruanda [...] are indisputably declaratory of customary international law» ${ }^{41}$.

Igual posición era mantenida por el TPIR en el caso contra el que fuera Jefe interino del Gobierno ruandés, Jean Kambanda, y por el Tribunal Espacial para Sierra Leona en el caso contra el Presidente de Liberia Charles Taylor, al subrayar la Sala de Apelaciones de dicho tribunal lo siguiente:

«We hold that the official position of the Applicant as an incumbent Head of State at the time when these criminal proceedings were initiated against him is not a bar to his prosecution by this Court» ${ }^{42}$.

Del mismo modo, si bien es cierto que las bases legales sobre las que se constituyen el TPIY y el TPIR difieren respecto de la Corte Penal Internacional, pues mientras que los primeros han sido establecidos mediante resoluciones del Consejo de Seguridad de conformidad con el Capítulo VII de la Carta de NNUU, la CPI se constituye mediante una norma convencional, el Estatuto de Roma, adoptada el 17 de julio de 1998, la CIJ en el asunto Arrest Warrant al referirse a la restricción de la inmunidad de los altos cargos estatales equipara dichos tribunales, no haciendo distinción en base a la naturaleza normativa de los mismos. Sin embargo, la CIJ parece apuntar que no para todos los tribunales internacionales opera tal restricción de la inmunidad, razón por la que se refiere a «ciertos tribunales internacionales».

41 The Prosecutor v. Anton Furundzija, ICTY Case n IT-95-17/1-T, Judgement, 10 December 1998, párr. 140; The Prosecutor v. Slobodan Milosevic, ICTY Case n IT-99-37-PT, Decision on Preliminary Motions, 8 November 2001, párr. 28.

42 The Prosecutor v. Charles Ghankay Taylor, Special Court for Sierra Leone, Appeals Chamber, Case Number SCSL-2003-1-AR72(E), Decision on Immunity from Jurisdiction, 31 May 2004, párrs. 51-52. 
Una lectura pausada del dictum nos llevaría a entender que tales palabras pretenden evitar los supuestos en los que dos o más Estados (por ejemplo Francia y Reino Unido) constituyeran un tribunal internacional con competencia para juzgar crímenes internacionales con el objeto de sortear las inmunidades que operan ante las jurisdicciones nacionales ${ }^{43}$. No obstante, la CPI no se incluye en esta categoría pues aspira a ejercer el ius puniendi de la comunidad internacional. Así lo corrobora el hecho de que su Estatuto haya sido ratificado por 124 Estados y que el Consejo de Seguridad le haya remitido dos situaciones que amenazaban -y siguen amenazando- la paz y la seguridad internacional.

Por tanto, mantenemos la existencia, en el Derecho internacional vigente, de una excepción consuetudinaria al principio de inmunidad de los Jefes de Estado cuando éstos estén acusados de la comisión de crímenes internacionales y sean sometidos ante órganos judiciales de la comunidad internacional, que afecta, no solo a la inmunidad funcional, sino, también, a la personal. Sostenemos dicho razonamiento siendo conscientes de la existencia de una práctica limitada (aunque coherente), en línea con lo que ha venido en denominarse «costumbre moderna ${ }^{44}$ que podría cristalizar sin la necesidad de una nutrida práctica. En todo caso, es cierto que la referida excepción consuetudinaria, que al menos hasta el caso $\mathrm{Al}$ Bashir no ha suscitado protestas significativas, ha nacido con una vulnerabilidad reseñable. De ahí la importancia de esclarecer los fundamentos jurídicos de las actuaciones de la CPI frente a los Jefes de Estado y la verdadera posición que los Estados africanos mantienen al respecto.

\section{2. ...Y en particular en el Estatuto de Roma: hacia la conciliación de la lectura conjunta de los artículos 27 y 98.1}

El Estatuto de Roma se asienta sobre el principio de responsabilidad penal individual, que es instituido con un «alcance universal» ${ }^{45}$. Así pues, la Corte será competente respecto de los que fueren mayores de 18 años en el

43 Así es entendido, entre otros autores, por KREss, C., «Las inmunidades...», op. cit., p. 22.

44 Sobre este concepto vid. RoberTs, A. E., «Traditional and Modern Approaches to Customary International Law: A Reconciliation», The American fournal of International Law, vol. $95, \mathrm{n}{ }^{\circ}$, 2001, pp. 757-791.

45 EsCOBAR HERNÁNDEZ, C., «La progresiva institucionalización de la jurisdicción penal internacional: la Corte Penal Internacional», en M. García Arán y D. López Garrido, Crimen internacional y jurisdicción universal», Valencia, Tirant lo Blanch, 2000, p. 250. 
momento de la comisión de crímenes de lesa humanidad, agresión, genocidio o crímenes de guerra con independencia de que el sujeto en cuestión ocupe o haya ocupado un cargo oficial.

El principio de improcedencia del cargo oficial se proclama en el artículo 27 del Estatuto bajo la siguiente redacción:

«1. El presente Estatuto será aplicable por igual a todos sin distinción alguna basada en el cargo oficial. En particular, el cargo oficial de una persona, sea Jefe de Estado o de Gobierno, miembro de un gobierno o parlamento, representante elegido o funcionario de gobierno, en ningún caso la eximirá de responsabilidad penal ni constituirá per se motivo para reducir la pena.

2. Las inmunidades y las normas de procedimiento especiales que conlleve el cargo oficial de una persona, con arreglo al derecho interno o al derecho internacional, no obstarán para que la Corte ejerza su competencia sobre ella».

En virtud del mencionado precepto, los Estados partes en el Estatuto de Roma han renunciado expresamente a toda inmunidad, tanto personal como funcional, que sus agentes pudieran haber tenido ante la Corte conforme al Derecho nacional e internacional ${ }^{46}$. Ahondando en su lectura, de su primer apartado se deriva la exclusión de cualquier tipo de inmunidad ratio materiae, en tanto que su segundo apartado hace lo propio respecto de cualquier tipo de inmunidad ratio personae ${ }^{47}$. Asimismo, de la conjunción de los principios de responsabilidad penal individual y de improcedencia del cargo oficial resulta, en palabras de C. Escobar, «la inoponibilidad a la Corte de cualquier forma de inmunidad de que pueda beneficiarse una persona en virtud del cargo que ocupa $\gg^{48}$. Sin embargo, no hay que obviar, por una parte, que el Estatuto de

46 AKANDE, D., «International Law...», op. cit., p. 420.

47 En esta línea se pronuncia GaETA, P., «Official Capacity and Immunities», en The Rome Statute of the International Criminal Court: a commentary, Oxford, Oxford University Press, 2002, pp. 990 y ss. Entre los autores españoles que defienden este análisis se encuentra CERvELL HoRTAL, M. J., «La resolución...», op. cit., p. 81.

48 Escobar HernáNDEZ, C., «La progresiva institucionalización...», op. cit., p. 252. Coincidimos con GAETA, P., «Official...», op. cit., pp. 990 y ss., cuando establece que la lectura del artículo 27 se debe hacer desde distintos planos. Así pues, el artículo 27 supone una plasmación de la excepción de Derecho consuetudinario que consagra la improcedencia del cargo oficial ante (determinados) tribunales internacionales, no pudiéndose alegar ningún tipo de inmunidad ratio materiae o ratio personae ante éstos. En cambio, en la relación triangular Corte, Estado requerido y tercer Estado parte, que analizaremos a continuación, el artículo 27.1 (referido a las inmunidades ratio materiae) y el art. 27.2 (referido a las inmunidades ratio personae) suponen una plasmación 
Roma no permite los juicios in absentia (art. 63.1) ${ }^{49}$, y, por otra, que para ejercer su competencia, la Corte precisa de la cooperación de los Estados parte en la investigación y el enjuiciamiento de los crímenes a los que se refiere el artículo 5 .

Junto a esta obligación general establecida en el precepto 86 del Estatuto se encuentran otras obligaciones específicas contenidas en su Parte IX, entre las cuales, la que reviste mayor interés a los efectos que nos ocupan, es el deber de los Estados parte de cumplir con las solicitudes de detención y entrega emitidas por la Corte (art. 89.1).

Nos encontramos ante una obligación «en principio absoluta» que solo se encuentra limitada por las «circunstancias especialísimas» contempladas en el artículo 98 del Estatuto ${ }^{50}$, estableciéndose en el primer párrafo del mencionado precepto, el cual tiene por rúbrica «Cooperación con respecto a la renuncia a la inmunidad y consentimiento a la entrega», lo siguiente:

«La Corte no dará curso a una solicitud de entrega o de asistencia en virtud de la cual el Estado requerido deba actuar en forma incompatible con las obligaciones que le imponga el derecho internacional con respecto a la inmunidad de un Estado o la inmunidad diplomática de una persona o un bien de un tercer Estado, salvo que la Corte obtenga anteriormente la cooperación de ese tercer Estado para la renuncia a la inmunidad» ${ }^{51}$.

de una norma convencional. Siguiendo con este argumento, la problemática se va a centrar en la relación triangular Corte, Estado requerido y tercer Estado no parte, puesto que para éstos últimos no rige la renuncia a la inmunidad que sus agentes pudieran ostentar cuando un Estado parte, en cumplimiento del deber de cooperar con la CPI, detenga y arreste al agente en cuestión para permitir que la Corte ejerza su competencia. No obstante, un sector doctrinal minoritario y la propia CPI en algunas de sus decisiones han defendido que la excepción de Derecho consuetudinario se extiende a la relación triangular mencionada. Tendremos ocasión de atender este debate doctrinal en sucesivas páginas.

49 Asimismo, se requiere la presencia del acusado durante la audiencia que tiene por objeto confirmar los cargos sobre la base de los cuales el Fiscal tiene la intención de pedir el procesamiento, salvo que concurran algunas de las circunstancias previstas en el artículo 62.1.

50 Vid. Escobar HernándeZ, C. «La Corte Penal Internacional: un instrumento al servicio de la paz» Revista internacional de filosofía politica, n. ${ }^{\circ} 21,2004$, p. 20. Ante tal obligación de cooperación «en principio absoluta» de los Estados parte respecto con la Corte también ha de tenerse en cuenta lo establecido en los artículos 89(2), 93(3) y (4), 94 y 95 del Estatuto.

51 Por su parte, el artículo 98.2 impide a la Corte solicitar la entrega de un ciudadano de un tercer Estado cuando el Estado requerido haya suscrito un acuerdo internacional conforme al cual se requiera previamente el consentimiento del Estado de la nacionalidad para entregar a la Corte a la persona en cuestión y dicho consentimiento no se hubiera obtenido. Quedarían incluido dentro de este precepto los tratados bilaterales celebrados por EEUU con Estados como Afganistán, 
La difícil lectura conjunta de los artículos 27 y 98.1, redactados por comisiones diferentes, ha ocasionado que la doctrina diverja en cuanto al contenido y alcance de éste último precepto. Algunos autores han defendido que el artículo 98.1 hace pervivir la inmunidad en todo caso, sin embargo, esta interpretación iría en contra del objeto y fin del Tratado, que no es otro que «acabar con el fenómeno de la impunidad estableciendo un nuevo sistema jurisdiccional ${ }^{52}$. La práctica posterior ha corroborado la inexactitud de esta posición.

Nos parece más apropiada la interpretación mantenida por un sector doctrinal en el que se encuentra el profesor C. Kreß, quien estuvo presente en el proceso de negociación y redacción de la Parte IX del Estatuto, y quien defiende que la finalidad del artículo 98.1 es evitar el posible conflicto de deberes que podría producirse cuando el cumplimiento de la obligación de cooperar con la Corte conduzca a un Estado parte a no respetar las inmunidades de otros Estados reconocidas por el Derecho internacional ${ }^{53}$. Siguiendo con este planteamiento, en el supuesto de que la entrega no tuviera lugar, no por ello se invalida la competencia de la Corte respecto del caso en cuestión, aunque de facto al no producirse dicha entrega se impide que la misma pueda ejercer su competencia. En otras palabras, el artículo 98.1 no compromete la competencia de la Corte, pero sí su ejercicio ${ }^{54}$.

Otra de las cuestiones respecto del artículo 98.1 que requieren de una aclaración es la expresión «tercer estado». No existe una posición unánime

Chad, Liberia, Honduras y Reino Unido, que tienen por objeto impedir la entrega de cualquier nacional estadounidense que fuera requerido por la Corte. El artículo 98.2 no va a ser objeto de nuestro estudio. Para un análisis más detallado de la cuestión vid. SERvín Rodríguez, C. A., Los acuerdos bilaterales de EE.UU.: ¿ una celada que limita la competencia de la Corte y pone en riesgo su efectividad?, Sevilla, Universidad Internacional de Andalucía, 2014, pp. 2-60.

52 Escobar Hernández, C., «La Corte...», op. cit., p. 21.

53 KRESS. C., «Las inmunidades...», op. cit., p. 15. Entre los autores que mantienen esta misma posición, vid. AKANDE, D., «International...», op. cit., p. 425, GAETA, P., «Official...», op. cit., p. 990; TriffTerer, O.; AmbOS, K., «Rome Statute of the International Criminal Court: a commentary», $3^{\text {a }}$ ed., Bloomsbury Publishing, Munich, 2016, p. 2120; Lirola Delgado, I.; Martín Martínez, M., «La Corte Penal Internacional: Fusticia versus Impunidad», Barcelona, Ariel, 2001, p. 145; CARNERERO CASTILla, R., «La inmunidad...», op. cit., p. 226. Ahondando en su razonamiento, para KRESS, C., «Las inmunidades...», op. cit., p. 14, aunque no se especifique en el precepto, el término «inmunidad» referido a la categoría de persona empleado en el artículo 98.1 incluye tanto las inmunidades ratio materiae, como las inmunidades ratio personae, puesto que de no seguirse esta interpretación, podríamos encontrarnos ante un conflicto de deberes que precisamente el artículo 98.1 pretende evitar.

54 Vid. Carnerero Castilla, R., «La inmunidad...», op. cit., p. 226. 
en la doctrina sobre si ha de entenderse como referida a los Estados que no son parte en el Estatuto o, por el contrario, a cualquier otro Estado aparte del requerido. Atendiendo a autores como P. Gaeta ${ }^{55}$ y D. Akanke ${ }^{56}$, $\ll$ to give meaningful effect to Article 27, Article 98(1) must be interpreted as applying only to officials of nonparties [...] Correspondingly, parties to the ICC Statute have an obligation under Part 9 to comply with the Court's requests for arrest and surrender where an official of another state party is on their territory».

Más precisa, sin embargo, nos parece la posición mantenida por C. Kreß, quien nos recuerda que las inmunidades mencionadas en el artículo 98.1 no solo están referidas a la categoría de personas sino también a la de bienes ${ }^{57}$. Ello explica el porqué, respecto de éstos, el término «tercer Estado» no solo se refiera a Estados no parte en el Estatuto, sino también a los Estados parte. Así pues, siguiendo con el planteamiento de este autor, las inmunidades relativas a locales diplomáticos de un tercer Estado parte no están cubiertas por la renuncia del artículo 27, por tanto, el artículo 98.1 exige que la Corte, ante tales propiedades, no pueda requerir la cooperación del Estado Parte donde se encuentren si previamente no ha conseguido obtener la renuncia a la inmunidad del tercer Estado parte propietario de dichos bienes. En cambio, respecto a la categoría de personas, los Estados parte han renunciado en el artículo 27 a la inmunidad que conlleva el cargo oficial, por ende, respecto de dicha categoría solo cabe entender el término «tercer Estado» referido a Estado no parte ${ }^{58}$.

Hemos de preguntarnos, por otro lado, si es la propia Corte la que debe determinar cuándo concurren las condiciones para que surta efecto el artículo 98.1 o, por el contrario, son los Estados parte quienes pueden decidir si sus obligaciones internacionales les comprometen.

55 Vid. GaETA, P., «Official...», op. cit., p. 990. Cabe mencionar que esta es la posición mantenida en las legislaciones nacionales de los Estados Parte en el Estatuto como Reino Unido, Canadá o Sudáfrica.

56 Vid. AKANDE, D., «International...», op. cit., p. 425.

57 De hecho, como expone KrEss, K., «Las inmunidades...», op. cit., p. 12, si atendemos al proceso de redacción del artículo 98.1 «las inmunidades diplomáticas relativas a la propiedad fueron el principal motor del precepto [...] siendo el ejemplo más notorio alegado en las negociaciones la inviolabilidad consuetudinaria de los locales diplomáticos tal como se estipula en el artículo 22 de la Convención de Viena sobre Relaciones Diplomáticas».

58 Con este planteamiento se resolvería la duda planteada por GAETA, P., «Official...», op. cit., p. 992, quien se pregunta por qué en la Parte IX del Estatuto relativa a la Cooperación y Asistencia judicial, mientras que en el resto de artículos se utiliza la expresión «Estado no parte», en el artículo 98.1 se utiliza el término «tercer Estado». 
Esta cuestión ha de responderse estableciendo que es la Corte la que debe valorar si una petición de cooperación puede situar a un Estado parte ante un conflicto de obligaciones. Ello se deriva de la propia redacción del artículo 98.1, pues su mandato se dirige a la Corte, y de la Regla 195.1 RPP, al señalar dicho precepto que es el Estado requerido al que se dirija una solicitud de entrega o de asistencia el que proporcionará toda la información que sirva a la Corte para aplicar el artículo 98.1. Asimismo, en palabras de C. Kreß, este modus operandi «ofrece una poderosa prueba por la determinación de los Estados parte para establecer un sistema de justicia colectiva con un fuerte componente vertical $\gg^{59}$.

Llegados a este punto hay que preguntarse si la obligación de cooperar con la Corte también se extiende a los Estados no parte. Para responder a esta pregunta, y como corolario de lo hasta ahora expuesto, cabe diferenciar dos niveles: por un lado, la relación vis-à-vis entre la Corte y el Estado del agente estatal, que opera desde un plano vertical y, por otro, la cooperación y asistencia judicial de los Estados con la CPI, que origina una relación triangular entre la Corte, el Estado requerido y el Estado del agente. De forma tal que, mientras del primero, «la exclusión de la inmunidad juega de forma absoluta»-en virtud del artículo 27 , que, a este respecto, es a su vez una norma declarativa de derecho consuetudinario ${ }^{60}$-, «en el segundo subsisten algunas manifestaciones de la inmunidad en su dimensión internacional»-que son previstas por el artículo $98.1-^{61}$, pues al no recepcionar el artículo 27 , en relación a éste segundo plano, una norma consuetudinaria, como establece el artículo 34 CVDT, un tratado internacional no puede crear obligaciones para un Estado no parte sin su consentimiento ${ }^{62}$. No obstante, como tendremos ocasión de analizar en el siguiente epígrafe, un sector doctrinal minoritario, así como la propia CPI en algunos de sus pronunciamientos parece haber mantenido la existencia de una costumbre internacional en relación a la obligación de cooperar con los tribunales internacionales que vincularía a todos los Estados, tanto a los que son Estados parte en el Estatuto como los que no lo son ${ }^{63}$.

59 KRESS, C. «The International Criminal Court and ties under International Law for States Not party to the Court's Statute», en M. Bergsmo, L. Yan, «State Sovereignty and International Criminal Law», Torkel Opsahl Academic Epublisher, Beijing, 2012, p. 232.

60 En consecuencia con lo mantenido en el epígrafe 2.1.B.

61 Vid. Escobar Hernández, C., «La Progresiva...», op. cit., pp. 251-254.

62 Pedretti, R., «Immunity of Heads of State and State Officials for International Crimes», Brill Nijhoff, Boston, 2015, p. 285; ILC, «Fifth report...», op. cit., párr.164.

63 En tal sentido se pronuncia KRESS, C., «Las inmunidades...», op. cit., p. 32 
En todo caso, una lectura conjunta del artículo 27 y del artículo 98.1 nos lleva a afirmar que las inmunidades que un agente del Estado ostente conforme al Derecho internacional no serán óbice para que la Corte tenga competencia en un caso concreto y le sea inoponible cualquier forma de inmunidad de que pueda beneficiarse una persona en virtud del cargo que ocupa ${ }^{64}$, si bien, el artículo 98.1 exige que, en el ejercicio de tal competencia, la CPI no requiera de los Estados Partes su asistencia y cooperación cuando ello podría dar lugar a una violación de sus obligaciones internacionales en materia de inmunidad. Teniendo en consideración que estas violaciones no podrían tener lugar (y por ende el artículo 98.1 no opera) en la relación triangular entre la Corte, Estado parte requerido y tercer Estado parte pues éstos han renunciado expresamente en virtud del artículo 27 a toda inmunidad, tanto personal como funcional, que sus agentes pudieran tener ante la Corte conforme al Derecho nacional e internacional ${ }^{65}$.

Por ende, pese a haber aclarado algunas aristas, aún se nos plantean cuestiones no resueltas. La problemática se centra especialmente en la relación triangular entre la Corte, el Estado requerido y el tercer Estado no parte, donde actúa el artículo 98.1, precepto que establece una remisión abierta al Derecho internacional y, como consecuencia, tal remisión ha ocasionado no pocas vacilaciones entre la doctrina, los legisladores nacionales e, incluso, en las decisiones de la Corte. Asimismo, en los supuestos en los que el Consejo de Seguridad sea quien remita la cuestión a la CPI (art. 13.b), surgen dudas sobre si, en virtud de tal remisión, se procede a la retirada de toda inmunidad que ostenten los agentes del Estado no parte implicado o, por el contrario, pervivirían, en su caso, tales inmunidades en la relación triangular Corte, Estado requerido y tercer Estado no parte.

Procederemos a examinar cada una de estas cuestiones con el análisis de los casos Al Bashir, Gaddafi, Kenyatta y Gbagbo, quienes, hasta el momento, han sido los Jefes o ex Jefes de Estado sobre los que la CPI ha abierto una causa.

64 Respecto a la relación entre competencia e inmunidad, la existencia de la primera constituye el punto de partida sobre el que se asienta la segunda. Así pues, «la inmunidad se configura ab initio como una restricción al ejercicio de aquella y, por tanto, es en sí misma un límite o excepción a la competencia jurisdiccional del Estado del foro». Vid. ILC, «Fifth report...», op. cit., párrs. 144 y ss.

65 En análoga posición se situarían los Estados que se encuentran en las circunstancias de los art. 12.3, y, como argumentaremos en el siguiente epígrafe, 13.b). Siendo conscientes de que respecto a esta última situación no existe una posición unánime en la doctrina. 


\section{ACtuaciones de la CPI sobre Jefes de Estado Africanos: PLASMACIÓN PRÁCTICA DE LA DISYUNTIVA TEÓRICA EN TORNO AL JUEGO DE LA INMUNIDAD EN EL ESTATUTO DE ROMA}

\subsection{El caso Al Bashir}

Las disquisiciones teóricas en torno al juego de las inmunidades en el Estatuto de Roma han tenido la ocasión de ser confrontadas en su vertiente práctica con el caso $\mathrm{Al}$ Bashir. El caso planteado es de una complicación considerable, pues, por un lado, es la primera vez que la CPI ha emitido una orden de arresto contra un Jefe de Estado en ejercicio y, por otro, Sudán es el primer Estado no parte sobre el que la Corte tiene competencia en virtud de una remisión efectuada por el Consejo de Seguridad de las Naciones Unidas conforme al artículo 13.b) del Estatuto ${ }^{66}$.

En breves líneas, Darfur es una región situada en el Sudán occidental cuyo conflicto detona en 2003 a raíz de la marginación a las que estaban sometidas las distintas etnias que habitaban la región por parte del Gobierno central. En este contexto de discriminación política y socioeconómica surgieron dos grupos rebeldes: el Movimiento de Liberación del Sudán (SLA) y el Movimiento de Justicia e Igualdad (JEM), quienes abogaban por la justicia y la igualdad entre las distintas etnias del país. Por su parte, el Gobierno central, liderado desde 1993 por Omar Hassan Al Bashir, reaccionó aliándose con el grupo paramilitar fanjaweed para silenciar las reivindicaciones. Con este fin, no solo atacaron a los grupos rebeldes JEM y SLA sino también a las tribus Fur, Masalit y Zaghawa a las que, en su mayoría, éstos pertenecían ${ }^{67}$. En 2004, el Consejo de Seguridad, tras instar a todas las partes a que pusieran fin a las violaciones de derechos humanos que estaban teniendo lugar, encomendó al Secretario General en la Resolución 1564 (2004) la creación de una Comisión Internacional para Darfur, la cual tuvo por mandato:

66 Conforme al artículo 13.b) ER, el Consejo de Seguridad, actuando con arreglo a lo dispuesto en el Capítulo VII de la Carta de las Naciones Unidas, puede remitir al Fiscal una situación en que parezca haberse cometido uno o varios de los crímenes a los que se refiere el artículo 5. Junto a dicho supuesto, la Corte podrá ejercer su competencia si un Estado parte remite una situación particular al Fiscal (art. 13.a ER), o si éste decide iniciar una investigación motu propio (art. 13.c ER).

67 Para un estudio detallado de la génesis y evolución del conflicto armado en Darfur, vid. LANGA Herrero, A., «Aproximación al conflicto armado en el Gran Darfur», Revista de Paz y Conflictos, vol. 8 , n. ${ }^{\circ} 1,2015$, pp. 151-178. 
«Investigar todas las denuncias de transgresiones del derecho internacional humanitario y las normas de derechos humanos cometidas, y constatar si se han producido o no actos de genocidio e identifique a los autores de tales transgresiones a fin de que los responsables rindan cuentas de sus actos» ${ }^{6}$.

Ante el informe presentado por la Comisión Internacional de Investigación para Darfur en febrero de $2005^{69}$, y en vistas que la situación estaba agravándose por momentos, el Consejo de Seguridad, decidió adoptar la Resolución 1593 (2005) de 31 de marzo, en virtud de la cual por vez primera remitía una cuestión a la $\mathrm{CPI}^{70}$. Hasta el momento, siete han sido los sudaneses pertenecientes a ambas partes del conflicto contra los que se ha abierto una causa $^{71}$. Si bien, en 2010 los cargos fueron retirados por falta de pruebas contra Abu Garda, líder rebelde del grupo armado JEM, y, debido a su fallecimiento, se concluyó el proceso en 2013 contra Mohammed Jerbo Jamus, igualmente miembro del JEM. Respecto de los casos activos, tres se encuentran en fase de cuestiones preliminares - casos Al Bashir, Harun-Ali Kushayb y Hussein- y uno en fase de primera instancia -caso Banda-.

Centrándonos en el tema que nos ocupa, dos órdenes de arresto han sido dictadas contra el Presidente de Sudán por parte de la CPI. En la primera, de 4 de marzo de 2009 se le acusa de la comisión de crímenes de guerra y crímenes

68 Resolución 1564 (2004) del Consejo de Seguridad, de 18 de septiembre de 2004, párr. 12. Disponible en: http://www.un.org/es/sc/documents/resolutions/2004.shtml [consultado: 13/06/2017].

69 Para un análisis de las conclusiones a la que llega el Informe de la Comisión Internacional de Investigación sobre Darfur, vid. YIHDEGO, Z., «Darfur and Humanitarian Law: The Protection of Civilians and Civilian Objects», Fournal of Conflict \& Security Law, vol. 14, n. ${ }^{\circ}$ 1, 2009, pp. 37 69. En el referido Informe la Comisión recomienda que el Consejo de Seguridad remita «de inmediato» la situación de Darfur a la Corte Penal Internacional.

70 La Resolución fue aprobada con 11 votos a favor, ninguno en contra y cuatro abstenciones: las de EEUU, China, Brasil y Argelia.

71 Recordemos que en los últimos años el conflicto de Darfur se ha recrudecido. Una vez alcanzada la independencia por parte Sudán del Sur se ha producido una ofensiva militar dirigida por las fuerzas armadas gubernamentales quienes han concentrado su arsenal contra los grupos rebeldes darfuríes, especialmente contra los rebeldes pertenecientes al Movimiento de Liberación de Sudán (SLA). Es en el curso de esta ofensiva donde organizaciones no gubernamentales como Amnistía Internacional y Human Rights Watch han denunciado la utilización de armas químicas contra la población civil. Vid. AMNISTÍA INTERNACIONAL, «Sudán: Indicios del uso de armas químicas en Darfur para matar y mutilar a cientos de civiles, incluidos niños y niñas», septiembre de 2016. Disponible en: https://www.es.amnesty.org/en-que-estamos/noticias/noticia/articulo/ sudan-hallados-indicios-creibles-del-uso-de-armas-quimicas-en-darfur-para-matar-y-mutilara-cien/ [consultado: 06/03/2017]. 
contra la humanidad ${ }^{72}$, incluyéndose en la segunda, de 12 de julio de 2010, el delito de genocidio ${ }^{73}$. Siguiendo la pauta establecida en el anterior epígrafe, procederemos al análisis de las inmunidades en el caso $\mathrm{Al}$ Bashir distinguiendo entre dos planos diferenciados aunque correlacionados: el de la relación visá-vis entre la CPI y Sudán y el de la cooperación y asistencia judicial de los Estados con la CPI.

\section{A) Relación vis-á-vis de la Corte con el Estado de Sudán}

En principio, la Corte no tenía competencia sobre lo acaecido en Darfur en tanto que se trata de una región de un Estado no parte que no había consentido de manera expresa en aceptar dicha competencia. No obstante, como ya ha sido apuntado, el Consejo de Seguridad en virtud de la Resolución 1593 (2005) de 31 de marzo remitió por primera vez la situación de un Estado no parte al Fiscal de la CPI, no requiriéndose en este supuesto, conforme a los dispuesto en el artículo 13.b) del Estatuto de Roma, que el Estado se encuentre vinculado por el mismo. De manera que en dicha Resolución el Consejo de Seguridad determinó lo siguiente:

«Actuando en virtud del Capítulo VII de la Carta de las Naciones Unidas, decide remitir la situación en Darfur desde el $1^{\circ}$ de julio de 2002 al Fiscal de la Corte Penal Internacional; [...] decide que el Gobierno del Sudán y todas las demás partes en el conflicto de Darfur deben cooperar plenamente con la Corte y el Fiscal y prestarles toda la asistencia necesaria en aplicación de la presente resolución».

Cuatro años después de la Resolución, el 4 de marzo de 2009, se dictó la primera orden de arresto contra el Presidente Al Bashir. En ella, desatinadamente, la Sala de Cuestiones Preliminares I solo trató la cuestión relativa a si las inmunidades que ostentan conforme al Derecho internacional los agentes de los Estados no parte en el Estatuto de Roma imposibilita la competencia de la Corte, pero, en cambio, no hizo mención alguna a si tales inmunidades

72 ICC, «Decision on the Prosecution's Application for a Warrant of Arrest against Omar Hassan Ahmad Al Bashir», 4 March 2009, Doc. ICC-02/05-01/09-3. La orden de arresto será dirigida al Gobierno sudanés, a los Estados Parte del Estatuto de Roma y a los miembros del CSNU no partes el ER. Vid. https://www.icc-cpi.int/darfur [consultado: 13/06/2017].

73 ICC, «Second Decision on the Prosecution's Application for a Warrant of Arrest», 12 July 2010, Doc. ICC-02/05-01/09-94. En el momento de escribir estas líneas Al Bashir está acusado de la comisión de 5 crímenes de lesa humanidad, dos crímenes de guerra y tres crímenes de genocidio. Vid. https://www.icc-cpi.int/darfur [consultado: 13/06/2017]. 
afectaban a la cooperación y asistencia de los Estados con la Corte. En otras palabras, respondió al primer plano que hemos planteado, esto es, la relación vis-à-vis entre la CPI y el Estado de Sudán y, sin embargo, no se refirió al juego de la inmunidad en la relación triangular entre la Corte, el Estado requerido y el Estado de Sudán ${ }^{74}$. Considera, pues, la Sala de Cuestiones Preliminares I que:

«The current position of Omar Al Bashir as Head of state which is not a party to the Statute, has no effect on the Court's jurisdiction over the present case» ${ }^{75}$.

Para defender esta posición aduce una serie de argumentos: primeramente alega el preámbulo del Estatuto, donde se establece que entre los objetivos del mismo se encuentra poner fin a la impunidad de los autores de los crímenes más graves de trascendencia para la comunidad internacional en su conjunto (párrs. 4 y 5), añadiendo como segundo argumento que el artículo 27 fue incluido en el Estatuto para lograr dicho objetivo esencial. A continuación, la Sala mantiene que en relación a la cuestión tratada no cabe recurrir al Derecho internacional más allá del Estatuto puesto que éste no deja laguna alguna al respecto, sosteniendo, como argumento de cierre, lo siguiente:

«By referring the Darfur situation to the Court, pursuant to article 13(b) of the Statute, the Security Council of the United Nations has also accepted that the investigation into the said situation, as well as any prosecution arising therefrom, will take place in accordance with the statutory framework provided for in the Statute, the Elements of Crimes and the Rules as a whole» ${ }^{76}$.

74 En palabras de AKande, D., «The Legal Nature of Security Council Referrals to the ICC and its Impact on Al Bashir's Immunities», Fournal of International Criminal fustice, vol. 7, $\mathrm{n}^{\circ} 2,2009$, p. 33 «The PTC's decision did not consider whether immunity is to be respected at the national level. This is a regrettable and an amazing oversight by the Chamber».

No obstante, algunos autores como KRESS, C., «Las inmunidades...», op. cit., p. 18, han querido entender que los argumentos expuestos en la orden de arresto de marzo de 2009 por la Sala de Cuestiones Preliminares I se referían implícitamente a la cuestión de que «el Derecho internacional de las inmunidades no impide a la CPI solicitar a un Estado parte detener y entregar al sospechoso» en tanto que la actuación del Consejo de Seguridad conforme al Capítulo VII de la Carta de NNUU «coloca a un Estado no parte en el Estatuto en una situación jurídica análoga a la de un Estado parte». Por tanto, para este autor, la denominada vía del Consejo de Seguridad, que explicaremos en líneas sucesivas, ya aparece implícitamente recogida en esta primera orden de arresto.

75 Vid. supra, nota 1, párr. 41.

76 Ibid., párr. 45. 
Ante tales argumentos, si bien llegamos a la misma conclusión que la Sala, el recorrido seguido para alcanzar dicha afirmación es diferente. En primer lugar no entendemos el porqué la Sala rechaza acudir más allá del Estatuto, cuando precisamente conforme al Derecho internacional general, como ha establecido la CIJ en el asunto Arrest Warrant, los altos cargos de un Estado «pueden ser sometidos a actuaciones penales ante ciertos tribunales internacionales donde éstos tengan competencia», como es el caso, añade, de la Corte Penal Internacional ${ }^{77}$. Igualmente, la Corte parece olvidar que el artículo 27 es un precepto de un tratado internacional, y, como tal, solo obliga a los Estados parte en el mismo, a menos que recoja un principio de Derecho internacional consuetudinario ${ }^{78}$.

Por otro lado, es adecuada la referencia a la Resolución del Consejo de Seguridad, pero la Corte no desarrolla su argumento. Así pues, como mantiene P. Gaeta y se deduce de las palabras de la Corte, dicha Resolución «serves to trigger the jurisdicción of the Court», pero la CPI no va más allá ${ }^{79}$.

En definitiva, como ha sido expuesto, la Sala en esta primera orden de arresto solo se refiere al primer plano de la problemática de la inmunidad, señalando acertadamente (aunque falla en su recorrido argumental) que la inmunidad de Al Bashir no rige en la relación vertical CPI-Estado de Sudán. Una vez realizada esta afirmación lo apropiado hubiera sido entrar de lleno en el segundo plano, esto es, si la inmunidad que ostenta $\mathrm{Al}$ Bashir impide a la Corte solicitar a un Estado parte detenerlo y entregarlo, cuestión donde entra en juego la lectura conjunta de los artículos 27 y 98.1 .

B) Relación triangular entre la Corte, el Estado requerido y el Estado de Sudán

Pese a su inaudito (y reprochado) silencio, la Corte se vio obligada a pronunciarse expresamente sobre la articulación de los preceptos 27 y 98.1 con ocasión de la reacción de determinados Estados parte frente al requerimiento de cooperar. Si bien, a este respecto, la argumentación mantenida por la CPI va ser modificada sin ni siquiera hacer alusión a tal giro jurisprudencial. Así pues, mientras que en las decisiones de 12 y 13 de diciembre de 2011, dirigidas respectivamente a Malawi y a Chad, la CPI se basó en la calificada por la doctrina como «vía del

77 Vid. supra nota 1, párrs. 25 y 26. Asimismo, el propio art. 98.1 ER hace una remisión abierta al Derecho internacional vigente.

78 GaETA, P., «Does President Al Bashir Enjoy Inmunity from Arrest?», Fournal of International Criminal fustice, vol. 7, n 2, 2009, p. 324.

79 Ibid., p. 324. 
derecho consuetudinario», en la decisión de 26 de febrero de 2014, dirigida a la República Democrática del Congo, la Corte adoptó la denominada «vía del Consejo de Seguridad». Analizaremos en las líneas siguientes cada una de ellas.

a) La vía del Derecho consuetudinario.

Tanto Kenia y Chad en 2010 como Yibuti y Malawi en 2011, todos ellos Estados Parte de la CPI, invitaron a Al Bashir a sus respectivos territorios. Ante esta situación, la Corte, en virtud de lo previsto en el artículo 87.7 del Estatuto $^{80}$, decidió adoptar una serie de decisiones donde, por una parte, se informaba de lo sucedido a la Asamblea de los Estados Parte y al Consejo de Seguridad y, por otra, se conminaba a los Estados concernidos a cooperar cumpliendo con las órdenes de arresto.

Por su parte, Malawi y Chad alegaron que, en tanto Sudán no era un Estado Parte, no le era de aplicación al Presidente Al-Bashir lo dispuesto en el artículo 27 del Estatuto, añadiendo en defensa de su posición una serie de declaraciones adoptadas por la UA en las que se instaba a sus Estados miembros a no cooperar con la CPI ${ }^{81}$. Como respuesta, la Sala de Cuestiones Preliminares I, en su decisión de 12 de diciembre de 2011 dirigida a Malawi, desestimaba tales argumentos y se refería, al fin, a la articulación entre los artículos 27 y $98.1^{82}$.

$\mathrm{Al}$ respecto, la Corte, tras efectuar un análisis sobre los precedentes históricos que defienden la inexistencia de inmunidad de los Jefes de Estados ante tribunales internacionales ${ }^{83}$, determinó lo siguiente:

«The Chamber finds that the principle in international law is that immunity of either former or sitting Heads of State can not be invoked to oppose a prosecution by an international court [...]

80 Según el cual, «Cuando, en contravención de lo dispuesto en el presente Estatuto, un Estado Parte se niegue a dar curso a una solicitud de cooperación formulada por la Corte, impidiéndole ejercer sus funciones y atribuciones de conformidad con el presente Estatuto, ésta podrá hacer una constatación en ese sentido y remitir la cuestión a la Asamblea de los Estados Partes o al Consejo de Seguridad, si éste le hubiese remitido el asunto».

81 Vid. CPI, Doc. ICC-02/05-01/138.

82 ICC, «Decision Pursuant to Article 87(7) of the Rome Statute on the Failure by the Republic of Malawi to Comply with the Cooperation Requests Issued by the Court with Respect to the Arrest and Surrender of Omar Hassan Ahmad Al Bashir», 12 December 2011, Doc. ICC-02/05-01/09-139.

83 Se refiere, entre otros, al Estatuto del Tribunal Militar Internacional de Nuremberg, a la Carta del Tribunal Internacional de Londres, a los Estatutos y jurisprudencia del Tribunal Penal Internacional para la ex Yugoslavia y del Tribunal Penal Internacional para Ruanda, al Proyecto de Códigos de Crímenes contra la paz y la seguridad internacionales y a la jurisprudencia de la CIJ, en concreto, al caso Arrest Warrant. 
The international community's commitment to rejecting immunity in circumstances where international courts seek arrest for international crimes has reached a critical mass and it is certainly no longer appropriate to say that customary international law immunity applies in the present context ${ }^{84}$.

\section{Para a continuación añadir que:}

«The Chamber finds that customary international law creates an exception to Head of State immunity when international courts seek a Head of State's arrest for the commission of international crimes. There is no conflict between Malawi's obligations towards the Court and its obligations under customary international law; therefore, article 98(1) of the Statute does not apply ${ }^{85}$.

Igual argumentación fue mantenida un día después por la Sala en su decisión de 13 de diciembre de 2011 dirigida al Chad $^{86}$. No haciéndose esperar la reacción de la Unión Africana al respecto, alentando a sus Estados Miembros a no cumplir con las resoluciones de la Corte sobre la base de su interpretación del artículo $98.1 \mathrm{ER}^{87}$.

La mayoría de la doctrina coincide en señalar la confusión del Tribunal entre la relación vertical CPI-Estado de Sudán y el deber de cooperación de

84 Ibid., párrs. 36 y 42.

85 Ibid., párr. 43. Algún autor apunta que faltaría mencionar en el razonamiento de la Sala el proyecto de artículo de la CDI o las resoluciones del IDI en materia de inmunidad. Vid. GuTIÉRREZ Espada, C.; Cervell Hortal, M. J., «Darfur...», op. cit., p. 194.

86 ICC, «Decision pursuant to article 87(7) of the Rome Statute on the refusal of the Republic of Chad to comply with the cooperation requests issued by the Court with respect to the arrest and surrender of Omar Hassan Ahmad Al Bashir», 13 December 2011, Doc. ICC-02/05-01/09-140.

$87 \mathrm{La}$ UA volvería a mantener la posición ya adoptada en la decimoquinta sesión ordinaria de la Asamblea de la Unión Africana donde mantuvo que «the AU Member States shall not cooperate pursuant to the provisions of Article 98 of the Rome Statute of the ICC relating to immunities, for the arrest and surrender of President Omar El Bashir of The Sudan». Vid. Assembly of the African Union Fifteenth Ordinary Session, July 2010, Kampala (Uganda). Doc. Assembly/AU/Dec.289-331 (XV). Más detallado fue el pronunciamiento en la decimoctava sesión ordinaria de la Asamblea de la UA, donde se estableció que: «the UA reaffirms its understanding that Article 98(1) was included in the Rome Statute establishing the ICC out of recognition that the Statute is not capable of removing an immunity which international law grants to the officials of States that are not parties to the Rome Statute». Vid. Assembly of the African Union Eighteenth Ordinary Session, January 2012, Addis Ababa (Ethiopia). Doc. Assembly/AU/Dec.391-415 (XVIII). La posición de la UA se sustentaba, por consiguiente, en afirmar que al no ser Sudán Estado parte en la CPI, para Al Bashir no rige el principio de improcedencia del cargo oficial consagrado en el artículo 27 del Estatuto de Roma, manteniendo éste las inmunidades que le reconoce el Derecho internacional como de manera expresa indicaría el artículo 98.1 del Estatuto. 
los Estados con la Corte. En este sentido, la Sala acierta en el primero, pero yerra respecto del segundo.

Entrando a analizar el fondo de la decisión, si bien es de agradecer que la Sala, a diferencia de su razonamiento de 4 de marzo de 2009, vaya más allá del Estatuto y se base en los principios de Derecho internacional general, así como en el Derecho internacional consuetudinario para mantener que la posición que ocupa $\mathrm{Al}$ Bashir como Jefe de Estado de Sudán no dificulta la competencia de la Corte, la cuestión de transcendencia a responder era si, teniendo en consideración el artículo 98.1, la Corte podía obligar a los Estados, en este caso a Malawi y Chad, a cooperar en el arresto de Al Bashir. La Sala efectúa un «tótum revolútum» y defiende que en base a los precedentes históricos analizados -que lo único que demuestran es la improcedencia del cargo oficial de los Jefes de Estado ante tribunales internacionales- y en su Estatuto -refiriéndose principalmente al artículo 27- la CPI se encuentra facultada para requerir a los Estados detener a un sujeto sospecho de haber cometido un crimen de Derecho internacional en aras de posibilitar a la Corte el ejercicio de su competencia ${ }^{88}$.

En este sentido, una de los argumentos clave de la decisión fueron los pronunciamientos del Tribunal para la antigua Yugoslavia emitidos con ocasión del juicio contra Slobodan Milosevic, donde la Corte defendió que el artículo 7.2 de su Estatuto, en el que se establece la improcedencia del cargo oficial, era una norma declarativa de Derecho consuetudinario. Sin embargo, en palabras de J. Abrisketa Uriarte, al mantener este razonamiento la Sala «confunde las bases jurídicas, puesto que el referido Tribunal se refiere a la inmunidad y al ejercicio de la jurisdicción, pero no al deber de cooperar ${ }^{89}$. Siguiendo con la citada autora, la Sala permanece en esta confusión al afirmar que:

«La inmunidad de los Jefes de Estado ha sido rechazada en numerosas ocasiones, cuando sostiene que ha crecido el número de procesos contra los Jefes de Estado ante los tribunales internacionales y cuando afirma que, en virtud del art. 27.2 del Estatuto, más de 120 Estados han renunciado a invocar la inmunidad de los Jefes de Estado» ${ }^{90}$.

88 CPI, «Decision Pursuant to Article 87(7) of the Rome Statute on the Failure by the Republic of Malawi to Comply with the Cooperation Requests Issued by the Court with Respect to the Arrest and Surrender of Omar Hassan Ahmad Al Bashir», 12 December 2011, Doc. ICC-02/0501/09-139, párr. 46.

89 Abrisketa URIARTE, J., «Al Bashir: ¿Excepción a la inmunidad...», op. cit., p. 36.

90 Ibid., p. 36. 
Pese a sus diferencias argumentales, P. Gaeta y D. Akande coinciden en la necesidad de distinguir entre los dos planos mencionados, y se preguntan que, de mantenerse el razonamiento de la Corte, debería aclarase porqué los Estados partes decidieron insertar en el Estatuto el artículo 98.191. También en este sentido se pronuncia D. Tladi ${ }^{92}$.

La respuesta implícita sugerida por la Corte sería, a juicio de M.J. Cervell Hortal que, desde la fecha de aprobación del Estatuto, el Derecho internacional «ha evolucionado de manera tan clara que algunos de sus artículos deben contemplarse desde una nueva perspectiva». No obstante, la autora señala que la CPI «no puede, sin más, considerar desfasado el contenido de un artículo incluido en un texto previamente acordado por los Estados sin seguir los procedimientos establecidos al efecto», teniendo en cuenta, más aún, la transcendencia de la cuestión tratada ${ }^{93}$. No, a menos que la costumbre internacional se haya modificado de una manera indiscutible. Hecho que no es demostrado por la Sala porque, como le reprueba la doctrina, en la fecha en la que la decisión fue tomada no existía práctica alguna al respecto ${ }^{94}$. Es más, el argumento de la Sala conduce a que sus conclusiones resulten aplicables a todos los Estados, ya sean parte o no, cuestión que complica más aún la defensa de su razonamiento. Así pues, atendiendo al párrafo 44 de la referida decisión:

«The Chamber is of the view that the unavailability of immunities with respect to prosecutions by international courts applies to any act of cooperation by States which forms an integral part of those prosecutions» (cursiva añadida).

En consecuencia, en su argumentación la Corte mantiene, sobre la base del Derecho internacional consuetudinario, la improcedencia del cargo oficial

91 Vid. GaETA, P., «Does President Al Bashir...», op. cit., pp. 315-332; AKande, D., «ICC Issues Detailed Decision on Bashir's Immunity (At long Last) But Gets the Law Wrong», EfIL Talk, 15 de diciembre de 2015.

92 Tladi, D., «The ICC Decisions on Chad and Malawi. On Cooperation, Immunities, and Article 98», Fournal of International Criminal fustice, vol. 11, $\mathrm{n}^{\circ}$ 1, 2013, pp. 199-221.

93 Cervell Hortal, M. J., «Darfur...», op. cit., p. 194

94 Cabe mencionar que en una posición minoritaria se encuentra KRESS, K., «Las inmunidades...», op. cit., p. 32, quien defiende que «la extensión de la vía del Derecho consuetudinario de la relación bilateral entre Corte y Estado de Sudán a la relación triangular no supone el reconocimiento de una regla diferente de Derecho internacional consuetudinario, sino la delimitación del ámbito de aplicación de la misma excepción de Derecho consuetudinario a la inmunidad ratione personae de Derecho internacional». Por tanto, concluye el citado autor que «al extender la vía del Derecho consuetudinario a la relación triangular en cuestión, la Sala de Cuestiones Preliminares no sobrepasó los límites de lo que constituye una actividad judicial internacional legítima». 
ante tribunales internacionales -la única de sus conclusiones con la que coincidimos-; que la improcedencia del cargo oficial ante tribunales internacionales se extiende a los actos de cooperación de los Estados con la Corte; y que respecto de tales actos de cooperación no se distingue si el Estado es parte o no del Estatuto.

Ante estas conclusiones, pese a ser la primera vez que la Corte trató expresamente la lectura conjunta de los artículos 27 y 98 (por otro lado con bastante retraso), no nos parece que haya mantenido una posición coherente, en tanto que ha confundido bases jurídicas y no ha argumentado una práctica ni una opinio iuris que sustente su razonamiento. Así pues, la Sala no atiende a la articulación de ambos preceptos, sino que, de facto, con su argumentación cercena la aplicación práctica del artículo 98 sin dar argumentos suficientes que sostengan esta posición. Por ello no es de extrañar que, ante la debilidad de sus argumentos unido a la protesta de la Unión Africana, se haya producido un viraje jurisprudencial.

b) La vía del Consejo de Seguridad.

Ante el inminente viaje de Al Bashir a la República Democrática del Congo con objeto de estar presente en la cumbre del Mercado Común para el Este y el Sur de África (COMESA), la Sala de Cuestiones Preliminares II adoptó la decisión de 26 de febrero de $2014^{95}$ por la que se requería a RDC, Estado parte en el Estatuto, arrestar y entregar a $\mathrm{Al}$ Bashir ante la Corte ${ }^{96}$. Pese a tal requerimiento, el Presidente de Sudán acudió a la cumbre y pudo salir de RDC sin ser detenido, lo que ocasionó una nueva decisión de la Sala solicitando explicaciones al respecto por no haber arrestado a $\mathrm{Al}$ Bashir y, en todo caso, no haber consultado a la CPI, de conformidad con el artículo 98.1, sobre si, en el caso concreto, existía alguna circunstancia que impidiera su detención ${ }^{97}$.

95 ICC, «Decision regarding Omar Al-Bashir's visit to the Democratic Republic of the Congo», 26 February 2016, Doc. ICC-02/05-01/09-186.

96 Fue el Fiscal quien notificó a la Sala el posible viaje de Al Bashir a RDC, instando a la Corte a adoptar las medidas necesarias para «(a) ensure that the pending warrants of arrest against Omar $\mathrm{Al}$ Bashir are executed; (b) enquire about said visit from the authorities of the DRC; and (c) remind the DRC authorities of their «standing obligation to arrest persons for whom warrants of arrest have been issued by the ICC». Vid. ICC, «Prosecution's Notification of Possible Travel in the Case of The Prosecutor v Omar Al Bashir», 25 February 2014, Doc. ICC-02/05-01/09-185.

97 ICC, «Transmission to Pre-Trial Chamber II of the observations submitted by the Democratic Republic of Congo pursuant to the 'Decision requesting observations on Omar Al-Bashir's visit to the Democratic Republic of Congo'», 17 March 2014, Doc. ICC-02/05-01/09-190. 
Al respecto, la República Democrática del Congo alegó tanto impedimentos de tiempo como legales ${ }^{98}$, argumentando respecto de los segundos que, por una parte, el Presidente de Sudán no había sido invitado por RDC sino por una organización regional, y, por otra, su obligación de cumplir con la decisión de 12 de octubre de 2013 adoptada por la UA, en la que se instaba a sus Estados miembros a no cooperar con la CPI cuando un Jefe de Estado en activo fuera sometido a una orden de arresto. Todo ello, según RDC, provocaba una situación «delicate and unmanageable» ${ }^{99}$. En respuesta, fue adoptada la decisión de 9 de abril de $2014^{100}$, donde la Sala comienza señalando que, si el cumplimiento de la orden de arresto situaba a RDC frente a una situación «delicada e inmanejable», conforme al artículo 97 del Estatuto y a la regla 195.1 RPP, las autoridades congoleñas deberían haber notificado a la Corte que dicha solicitud de entrega planteaba un problema de ejecución en relación con el artículo 98.1 del Estatuto. Actuación que no fue emprendida ${ }^{101}$. Por su parte, respecto a la problemática de la inmunidad, la Corte cambia su jurisprudencia para rebatir los argumentos de RDC sin ni siquiera hacer mención a las razones de tal giro jurisprudencial, hecho que le ha valido importantes críticas por parte de la doctrina ${ }^{102}$.

Adelantamos que con esta nueva posición, la CPI vuelve a errar al tratar el primer plano planteado, aunque, a diferencia de las anteriores, su razona-

98 ICC, «Annex II to Transmission to Pre-Trial Chamber II of the observations submitted by the Democratic Republic of Congo pursuant to the 'Decision requesting observations on Omar AlBashir's visit to the Democratic Republic of Congo'», p. 6. Doc. ICC-02/05-01/09-190-Annex-II. 99 Ibid., p. 6.

${ }^{100}$ ICC, «Decision on the Cooperation of the Democratic Republic of the Congo Regarding Omar Al Bashir's Arrest and Surrender to the Court», 9 April 2014, Doc. ICC-02/05-01/09-195.

Respecto a las alegaciones de falta de tiempo, RDC adujo que COMESA había comunicado la composición de las delegaciones que acudirían a RDC con muy poco tiempo de antelación y que la decisión de arresto de la Corte fue emitida el mismo día en el que Al Bashir llegó al RDC. En respuesta la Sala recuerda que, ya cuatro años antes, concretamente el 6 de marzo de 2009, fue emitida por la Secretaría de la CPI una solicitud de detención y entrega de Omar Al Bashir, imputado por la comisión de crímenes de guerra y de lesa humanidad, dirigida a todos los Estados partes en el Estatuto. A la que se unió una segunda solicitud el 21 de julio de 2010, esta vez incluyéndose el cargo de genocidio (párrs. 12 y ss.)

101 Ibid., párr. 15.

102 En palabras de GaETA, P., «The ICC Changes Its Mind on Immunity from Arrest of President Al Bashir, But It Is Wrong Again», Opinio Iuris blogpost, 23 de abril de 2014 en http://opiniojuris. org/2014/04/23/guest-posticc-changes-mind-immunity-arrest-president-al-bashir-wrong «the Court cannot take the luxury of changing its mind on a sensitive issue such as that of the immunities of Al Bashir without even saying why». Por su parte, ABRISKETA URIARTE, J., «Al Bashir..., op. cit., p. 43, señala que «[si la Corte] hubiera rescatado su argumentación anterior, basada en la costumbre internacional, habría contribuido a la cristalización de la misma». 
miento tiene una mayor solidez argumental respecto del segundo. Así pues, en referencia a la relación vis-á-vis entre la CPI y el Estado de Sudán, mientras que acertadamente en la Decisiones de 2011 dirigidas a Malawi y Chad se basaba en la improcedencia del cargo oficial ante tribunales internacionales sobre la base del Derecho internacional consuetudinario, siendo, en este sentido, el artículo 27 una norma declarativa de Derecho consuetudinario, en esta decisión la Corte exclusivamente hace alusión al mencionado precepto con las siguientes palabras:

«An exception to the personal immunities of Heads of States is explicitly provided in article 27(2) of the Statute for prosecution before an international criminal jurisdiction. According to this provision, the existence of personal immunities under international law which generally attach to the official capacity of the person «shall not bar the Court from exercising its jurisdiction over such a person». ${ }^{103}$

Parece deducirse que la Corte vuelve a retomar la posición errada ya mantenida por la Sala de Cuestiones Preliminares I en la Orden de arresto de 4 de marzo de 2009 donde se establecía que «no cabe ir más allá del propio Estatuto ${ }^{104}$, puesto que éste no presenta ninguna laguna en la cuestión relativa a la inmunidad ${ }^{105}$. En cambio, un razonamiento más sólido es mantenido respecto de la relación triangular Corte, Estados requerido y Estado de Sudán.

La Sala se alejó del intrincado terreno del Derecho internacional consuetudinario y mantuvo que para darle pleno sentido a la Resolución 1593 (2005) CSNU en la que se establecía que «el Gobierno del Sudán [...] debe cooperar plenamente con la Corte y con el Fiscal y prestarles toda la asistencia necesaria en aplicación de la presente resolución» ${ }^{106}$, dicho «deber de cooperar plenamente» ha de ser entendido en el sentido de que implícitamente el Consejo de Seguridad ha procedido a retirar las inmunidades de las que goza Al Bashir. Así pues, en palabras de la Sala:

«Since immunities attached to Omar Al Bashir are a procedural bar from prosecution before the Court, the cooperation envisaged in said resolution was meant to eliminate any impediment to the proceedings before the

\footnotetext{
103 Ibid., p. 12.

${ }^{104}$ Junto al Estatuto la Sala mencionaba las Reglas de Procedimiento y Prueba y los Elementos de los Crímenes.

105 Vid. supra, nota 72 , párr. 44.

106 Vid. supra, nota 99, párr. 14.
} 
Court, including the lifting of immunities. Any other interpretation would render the SC decision requiring that Sudan «cooperate fully» and «provide any necessary assistance to the Court» senseless» ${ }^{107}$.

En consonancia con esta argumentación, al serle retirada la inmunidad a Al Bashir en virtud (del lenguaje) de una Resolución adoptada en el marco del Capítulo VII de la Carta de las Naciones Unidas, no existe impedimento alguno en el plano horizontal (art. 98.1) entre la República Democrática del Congo y Sudán, encontrándose facultado aquel para arrestar a Omar Al Bashir ${ }^{108}$.

Con respecto a la posición de la Unión Africana, siguiendo con su razonamiento, la Sala entiende que no se produce una confrontación entre la CPI y la UA, sino entre las decisiones adoptada por ésta y la Resolución 1593 (2005) del Consejo de Seguridad. Debiendo ser solucionado este conflicto atendiendo a los artículos 25 y 103 de la Carta de la ONU, en los que se establece que los Miembros de las Naciones Unidas deben cumplir las decisiones del Consejo de Seguridad de acuerdo con la Carta y que en caso de conflicto entre las obligaciones contraídas por los Miembros de las Naciones Unidas en virtud de la presente Carta y sus obligaciones contraídas en virtud de cualquier otro convenio internacional, prevalecerán las obligaciones impuestas por la primera ${ }^{109}$.

${ }^{107}$ Añadiendo a continuación la Sala que «the «cooperation of that third State [Sudan] for the waiver of the immunity», as required under the last sentence of article 98(1) of the Statute, was already ensured by the language used in paragraph 2 of SC Resolution 1593(2005). By virtue of said paragraph, the SC implicitly waived the immunities granted to Omar Al Bashir under international law and attached to his position as a Head of State», vid. supra, nota 99, párr. 14.

$108 \mathrm{Ibid}$., p. 14. Esta posición va a ser la mantenida hasta el momento en sucesivos pronunciamientos. Vid. ICC, «Decision on the non-compliance by the Republic of Uganda and Republic of Djibouti with the request to arrest and surrender Omar Al-Bashir to the Court and referring the matter to the United Nations Security Council and the Assembly of State Parties to the Rome Statute», 11 July 2016, n. ${ }^{\circ}$ ICC-02/05-01/09, párr.11 y ss.; ICC, «Decision under article 87(7) of the Rome Statute on the non-compliance by South Africa with the request by the Court for the arrest and surrender of Omar Al-Bashir», 6 July 2017, Doc. n. ${ }^{\circ}$ ICC-02/05-01/09, párrs. 48 y ss. En relación a este último pronunciamiento, si bien la Sala evita pronunciarse sobre el primer plano planteado (párr. 69), ésta expresamente rechaza la existencia de una excepción consuetudinaria que alcance a la relación triangular Corte, Estado parte requerido y tercer Estado no parte del agente, contradiciendo, por tanto, lo mantenido en las Decisiones de 12 y 13 de diciembre de 2011, dirigidas respectivamente a Malawi y a Chad (párr. 68).

109 A este respecto, en palabras de la CIJ, Opinión consultiva sobre las consecuencias jurídicas que tiene para los Estados la continuación de la presencia de Sudáfrica en Namibia (África Sudoccidental), no obstante lo dispuesto en la Resolución 276 (1970) del Consejo de Seguridad, CIf Recueil, 1971, párr. 116, «when the Security Council adopts a decision under article 25 in accordance with the Charter, it is for member States to comply with that decision [...]. To hold otherwise would be to deprive this principal organ of its essential functions and powers under the Charter». 
Ante el pronunciamiento de la Corte respecto al plano vertical, si bien es de reconocer su mayor consistencia argumental, sobre todo en relación a la pretendida confrontación entre las decisiones de la CPI y la UA, coincidimos solo en parte con el mismo, pues en nuestra opinión y en línea con el razonamiento ya apuntado por Akande ${ }^{110}$ y Pedretti ${ }^{111}$, es la propia remisión del CSNU -y no el lenguaje utilizado en la misma- la que conlleva -a todos los efectos- que el Estado se sitúe en una posición análoga a la de un Estado parte, y, por ende, le sea aplicable el artículo 27 del Estatuto como a cualquier otro Estado que lo hubiera ratificado. De ahí que en la relación triangular Corte, Estado requerido y Estado del agente no rigen las inmunidades que han de ser respetadas de conformidad con el art. 98.1.

Respecto a los Estados no parte, si bien la Sala evita pronunciarse al respecto, entendemos que la obligación de cooperar no les alcanza porque así se deriva de la Resolución 1593 (2005). Si el CSNU se hubiera pronunciado en otro sentido, los Estados no parte también se verían obligados a cooperar con la Corte, pues el artículo 25 y 103 de la Carta de las NNUU así lo exigen ${ }^{112}$.

Por último, se siga una línea jurisprudencial u otra, es pacífico afirmar que es la Corte, como se deriva de la propia redacción del artículo 98.1 y de la Regla 195.1 RPP, la que debe valorar si una petición de cooperación puede situar a un Estado parte ante un conflicto de obligaciones. Por ende, la decisión unilateral de los Estados parte de no cumplir con los requerimientos de la Corte infringe el Estatuto de Roma.

\subsection{Caso Gadafi}

Las revueltas árabes que se iniciaron a finales de 2010 en Túnez y llegaron a Libia en febrero de 2011 amenazaron la pervivencia del régimen de Muamar Abu-minyar el Gadafi, quien ocupaba el cargo de Jefe del Estado libio desde hacía más de 40 años. Para mantenerse en el poder, dichas protestas pacíficas fueron reprimidas con una violencia extrema y, ante dicha situación, el Consejo de

\footnotetext{
110 AKande, D., «The Legal Nature...», op. cit., p. 342.

111 PEDRETTI, R., «Immunity...», op. cit., p. 287.

112 Así pues, en el párrafo segundo de la Resolución 1593 (2005) CSNU se establece que pese a reconocerse que «los Estados que no son partes en el Estatuto de Roma no tienen obligación alguna con arreglo a dicho Estatuto, se exhorta a todos los Estados [...] a que también cooperen plenamente» (cursiva añadida).
} 
Seguridad de Naciones Unidas, actuando conforme al Capítulo VII de la Carta de las NNUU, adoptó la Resolución 1970 (2011) de 26 de febrero ${ }^{113}$, en virtud de la cual, entre otras medidas, decidió remitir la cuestión libia a la Corte Penal Internacional. Dicha remisión se redacta en términos prácticamente idénticos a la Resolución 1593 (2005) relativa a Darfur ${ }^{114}$, al establecer que:

[El Consejo de Seguridad] decide remitir la situación imperante en la Jamahiriya Árabe Libia desde el 15 de febrero de 2011 al Fiscal de la Corte Penal Internacional. [...] Las autoridades libias deben cooperar plenamente con la Corte y el Fiscal y prestarles toda la asistencia necesaria de conformidad con la presente resolución, y, aunque reconoce que los Estados que no son partes en el Estatuto de Roma no tienen obligación alguna en virtud de él, insta a todos los Estados y organizaciones regionales y demás organizaciones internacionales competentes a que cooperen plenamente con la Corte y el Fiscal ${ }^{115}$.

Tres meses más tarde y de conformidad con la solicitud emitida en mayo de 2011 por el Fiscal Moreno Ocampo, la Sala de Cuestiones Preliminares I adoptó tres órdenes de arresto dirigidas contra «Muamar Abu Minyar Gadafi -Jefe de Estado libio-, Saif Al Islam Gadafi -su hijo y Primer Ministro de facto del país- y Abdullah Al Senussi -Jefe de la Inteligencia Militar- ${ }^{116}$ por la comisión de crímenes de lesa humanidad cometidos a partir del 15 de febrero de 2011 en varias ciudades libias ${ }^{117}$. Respecto a la cuestión de las inmunidades, la Sala apenas le dedica un párrafo, señalando al respecto lo siguiente:

Insofar as the situation in Libya has been referred to the Court by the Security Council acting pursuant to article 13(b) of the Statute, the present case falls within the jurisdiction of the Court despite the fact that it concerns

113 A diferencia de la Resolución 1593 (2005) que remitía la cuestión de Darfur a la CPI dicha resolución fue aprobada por unanimidad. Puede ser objeto de consulta en: http://www.un.org/es/ comun/docs/?symbol=S/RES/1970\%20(2011) [consultado: 13/06/2017].

${ }^{114}$ Cabe destacar las similitudes con la situación de Darfur, pues tanto Sudán como Libia no son Estados parte del Estatuto de Roma, la CPI ha conocido ambos asuntos en virtud de la remisión efectuada por el CSNU y tanto Gadafi como Al Bashir han sido Jefes de Estado en activo en el momento en el que se iniciaron las investigaciones.

$115 \mathrm{Ibid}$., párr. 4 y 5.

116 Cervell Hortal, M. J., «La Resolución 1970...», op. cit., p. 78

117 ICC, «Decision on the 'Prosecutor's Application Pursuant to Article 58 as to Muammar Mohammed Abu Minyar Gaddafi, Saif Al-Islam Gadafi and Abdullah Alsenussi’», 27 June 2011, Doc. ICC-01/11-01/11-1. 
the alleged criminal liability of nationals of a State that is not party to the Statute and for crimes which have been committed in the territory of a State that is not party to the Statute. At this juncture, the Chamber also notes that, consistent with its findings in the Al Bashir Case, the official position of an individual, whether he or she is a national of a State party or of a State which is not party to the Statute, has no effect on the Court's jurisdiction ${ }^{118}$.

En otras palabras, la Sala de Cuestiones Preliminares I tan solo se refiere al hecho de que el Consejo de Seguridad haya activado la jurisdicción de la Corte en un caso en el que inicialmente ésta no tenía competencia y nos recuerda el principio de improcedencia del cargo oficial ante la CPI, remitiéndose por lo demás a lo mantenido en el caso del Presidente de Sudán. No obstante, como ha sido expuesto en el anterior epígrafe, en el caso Al Bashir la Corte ha variado su jurisprudencia respecto al fundamento de la improcedencia del cargo oficial en relación a los agentes de Estados no parte en el Estatuto, por tanto no deja claro a cuál de sus razonamientos atenernos ${ }^{119}$. Asimismo, en dicha decisión ni siquiera se hace mención a la problemática de la inmunidad en la relación triangular Corte, Estado requerido y Estado de Libia.

Este silencio (muy criticado por la doctrina ${ }^{120}$ ) también estará presente en las solicitudes de detención y entrega dirigidas a Libia, a los Estados parte en el Estatuto de Roma, a los Estados vecinos de Libia y a los Estados no parte en el Estatuto de Roma que son miembros del Consejo de Seguridad ${ }^{121}$.

\footnotetext{
118 Ibid., párr. 9.

${ }^{119}$ Cabe mencionar que si atendemos a la nota a pie de página que incluye este párrafo y que señala el número de documento ICC-02/05-01/09-3, podemos entender que la Corte se remite al razonamiento mantenido en la decisión de 4 de marzo de 2009.

120 Cervell Hortal, M. J., «La Resolución 1970...», op. cit., p. 88.

${ }^{121}$ CPI, «Solicitud de detención y entrega de Muammar Mohammed Abu Minyar Gadafi, Saif AlIslam Gadafi y Abdullah Al Senussi dirigida a todos los Estados Partes en el Estatuto de Roma», 4 de julio de 2011, Doc. n. ${ }^{\circ}$ ICC-01/11-01/11; ICC, «Request to States neighboring the Libyan Arab Jamahiriya for the arrest and surrender of Muammar Mohammed Abu Minyar Gadafi, Saif Al-Islam Gadafi and Abdullah Al Senussi», 4 July 2011, Doc. $n^{\circ}$ ICC-01/11-01/11; ICC, «Request to the United Nations Security Council members that are not States Parties to the Rome Statute for the arrest and surrender of Muammar Mohammed Abu Minyar Gadafi, Saif Al-Islam Gadafi and Abdullah Al-Senussi», 4 July 2011, Doc. $\mathrm{n}^{\circ}$ ICC-01/11-01/11. Atendiendo a tales solicitudes de detención y en línea con la Resolución 1970 (2011) CSNU de 26 de febrero, mientras que para los Estados parte del ER la Sala utiliza la expresión «request to cooperate», para los Estados no Parte miembros del Consejo de Seguridad se emplea la expresión «invite to cooperate». Como mantuvimos en el caso Al Bashir, en nuestra opinión, es correcto señalar que la obligación de cooperar con la Corte no alcanza a los Estados no parte del ER, pues así se desprende de la Resolución del CSNU.
} 
El curso de los acontecimientos ha ocasionado que la problemática de la inmunidad en relación a la cuestión libia haya desaparecido, pues en octubre de 2011 se produjo la muerte de Muamar Gadafi ${ }^{122}$. De igual modo, en la actualidad su hijo tiene la consideración de ex primer ministro ${ }^{123} \mathrm{y}$, por tanto, como señalamos en páginas anteriores, éste solo disfruta de inmunidad ratio materiae, siendo pacífico afirmar que ante crímenes internacionales tal inmunidad no puede ser alegada frente a tribunales internacionales. Postura también mantenida por la Unión Africana. No obstante, con este caso, la Corte de nuevo perdió una oportunidad de aclarar la lectura conjunta de los artículos 27 y 98 del Estatuto, asentando una jurisprudencia coherente al respecto.

\subsection{Caso Kenyatta}

Tras las elecciones presidenciales que tuvieron lugar en Kenia en diciembre de 2007 se produjo una oleada de enfrentamientos tribales, fundamentalmente entre las etnias Kikuyu -defensores del vencedor Mwai Kibaki- y Kalenjin -seguidores del opositor Odinga- que desembocaron en violaciones sistemáticas de derechos humanos ${ }^{124}$. Según datos constatados por la CPI más de 1000 personas fueron asesinadas, se cometieron más 900 actos documentados de secuestro y violencia sexual y en torno a 350.000 keniatas se vieron obligados a desplazarse de su lugar de residencia ${ }^{125}$.

122 ICC, «Decision to Terminate the Case Against Muammar Mohammed Abu Minyar Gaddafi», 22 November 2011, n ${ }^{\circ}$ ICC-01/11-01/11-28.

${ }^{123}$ El devenir del caso Saif Al Islam Gadafi es representativo de la situación caótica en la que Libia se encuentra. En la actualidad existen tres gobiernos incompatibles entre sí: uno en Trípoli, de corte islamista, otro en Tobruk, elegido mediante sufragio en 2014 y que cuenta con el apoyo del Ejército Nacional Libio y otro «de unidad nacional» instaurado en 2016, que, si bien su fuerza en el terreno es muy limitada, es el que cuenta con el reconocimiento de la ONU y de la Comunidad internacional. Al respecto, mientras que el Gobierno de Trípoli ha condenado a muerte a Saif Al Islam Gadafi, el Gobierno de Tobruk ha indultado al ex primer ministro quien al estar retenido durante más de cinco años por una milicia afín al Gobierno de Tobruk, ha sido puesto en libertad en junio de 2017. Por su parte, la CPI recientemente ha recordado la obligación de las autoridades libias de cooperar con la Corte y la invalidez de dicha amnistía. Vid. ICC, «ICC Prosecutor calls for the immediate arrest and surrender of the suspects, Mssrs Saif Al-Islam Gaddafi», 14 June 2017.

124 AMNISTÍA INTERNACIONAL, «Kenia: protejan los derechos humanos», nota de prensa de 17 de enero de 2016. Disponible en: https://www.es.amnesty.org/actua/acciones/kenia-protejan-losderechos-humanos/ [consultado: 20/06/2017].

125 El resultado de las elecciones de diciembre de 2007 dio como vencedor al Partido de Unidad Nacional (PNU por sus siglas en inglés) liderado por Mwai Kibaki, quien contaba con el apoyo de la etnia Kikuyu. Por su parte, el Movimiento Democrático Naranja (ODM por sus siglas en inglés) liderado por Raila Odinga y apoyado por la etnia Kalenjin quedó en segunda posición. Tras 
Centrándonos en el papel de la CPI en Kenia, las diferencias con Sudán y Libia son significativas: desde 2005 Kenia es Estado Parte en el Estatuto de Roma y la cuestión no fue remitida por el Consejo de Seguridad de la ONU, sino que, por vez primera, el Fiscal solicitó abrir una investigación por iniciativa propia conforme al artículo 15 del Estatuto.

Al respecto, el 31 de marzo de 2010, la Sala de Cuestiones Preliminares II autorizó al Fiscal la apertura de una investigación relativa a la presunta comisión de crímenes de lesa humanidad en el periodo postelectoral 2007$2008^{126}$. El 15 de diciembre de 2010 el Fiscal solicitó a la Sala de Cuestiones Preliminares II que adoptara órdenes de comparecencia contra Uhuru Muigai Kenyatta, William Samoei Ruto, Joshua Arap Sang, Henry Kiprono Kosgey, Francis Kirimi Muthaura, y Mohammed Hussein Ali, todos ellos por su presunta participación en las referidas violaciones de derechos humanos ${ }^{127}$. Estas órdenes fueron emitidas por la Sala el 8 de marzo de $2011^{128}$.

En un principio las autoridades keniatas mostraron su apoyo a la CPI, pero debido a que cinco de los seis sospechosos sobre los que el Fiscal solicitó órdenes de comparecencia ocupaban cargos en el Gobierno de coalición constituido tras el periodo de violencia postelectoral, la postura mantenida hasta entonces cambió. Inicialmente pretendieron hacer uso del principio de complementariedad para suspender la investigación por parte de la CPI. Para

conocerse los resultados numerosas voces en el país, incluidas las misiones internacionales de observación electoral, denunciaron que los procesos de votación y recuento de votos habían sido fraudulentos. Ante los graves episodios de violencia postelectoral y bajo la mediación del ex secretario general de las Naciones Unidas Kofi Annan fue establecido un Gobierno de coalición donde Mwai Kibaki ostentaba el cargo de Presidente y Raila Odinga el de Primer Ministro.

${ }^{126}$ ICC, «Decision Pursuant to Article 15 of the Rome Statute on the Authorization of an Investigation into the Situation in the Republic of Kenya», de 31 March 2010, $\mathrm{n}^{\circ}$ ICC-01/09-19.

127 El Fiscal Moreno Ocampo en diciembre de 2010 presentó dos casos: el primero contra William Samoei Ruto, Henry Kiprono Kosgey y Joshua Arap Sang y el segundo contra Francis Kirimi Muthaura, Uhuru Muigai Kenyatta y Mohammed Hussein Ali. Todos ellos acusados de cometer crímenes de lesa humanidad. Posteriormente, la Fiscal Fatou Bensouda ha presentado el 18 de julio de 2013 y el 9 de febrero de 2015 respectivamente dos casos más: el primero referido a Walter Osapiri Barasa y el segundo contra Paul Gicheru y Philip Bett. En estos nuevos casos, en la actualidad los únicos abiertos, los sospechosos están acusados de la comisión de delitos contra la administración de justicia.

${ }^{128}$ ICC, «Decision on the Prosecutor's Application for Summonses to Appear for Francis Kirimi Muthaura, Uhuru Muigai Kenyatta and Mohammed Hussein Ali», 8 March 2011, n. ${ }^{\circ}$ ICC-01/0902/11-1; «Decision on the Prosecutor's Application for Summons to Appear for William Samoei Ruto, Henry Kiprono Kosgey and Joshua Arap Sang», 8 March 2011, n. ${ }^{\circ}$ ICC-01/09-01/11-1.

Cabe mencionar que ante estas órdenes de comparecencia los seis sospechosos se presentaron voluntariamente ante la Corte en abril de 2011, siendo Kenyatta el primer Jefe de Estado en activo en ser juzgado por la CPI. 
ello, se aprobó una Ley de Crímenes Internacionales y se creó una nueva Sala en el Tribunal Supremo dedicada a Crímenes Internacionales. No obstante, con estas medidas no se lograron resultados $\operatorname{concretos}^{129}$. Frustrada su pretensión, el Gobierno keniata, apoyándose en la Unión Africana, inició una fuerte ofensiva diplomática contra la CPI. Esta tensión fue en aumento cuando el 23 de enero de 2012 la Sala Segunda de Cuestiones Preliminares confirmó los cargos contra Uhuru Kenyatta, William Ruto, Francis Muthaura, y Joshua Sang acusados de cometer presuntamente crímenes de lesa humanidad ${ }^{130}$.

Nos centraremos en los procesos contra Uhuru Kenyatta y William Ruto, pues, en ellos, el tema de la inmunidad fue tratado por la Corte ${ }^{131}$. Kenyatta y Ruto eran adversarios políticos, pero dejaron atrás sus diferencias para vencer

129 Vid. AnaYa López, V. J., «África y la Corte Penal Internacional: logros y desafíos. Las situaciones de Darfur, Kenia y Libia», Málaga, Universidad de Málaga, 2015, p. 55.

130 Ibid., vid. ICC, «Decision on the Confirmation of Charges Pursuant to Article 61(7)(a) and (b) of the Rome Statute (Case of the Prosecutor v. Francis Kirimi Muthaura, Uhuru Muiga Kenyatta and Mohammed Hussein Ali)», 23 January 2012, n. ${ }^{\circ}$ ICC-01/09-02/11-382-Red; «Decision on the Confirmation of Charges Pursuant to Article 61(7)(a) and (b) of the Rome Statute (Case of the Prosecutor v. William Samoeiruto, Henry Kiprono Kosgey and Joshua Arap Sang)», 23 January 2012, n. ${ }^{\circ}$ ICC-01/09-02/11-382-Red.

131 Respecto a la posición mantenida por la Unión Africana, en tanto que Kenia, a diferencia de Sudán, es Estado Parte del Estatuto de Roma, no resultaba de aplicación el argumento mantenido en el caso Al Bashir relativo a la articulación de los preceptos 27 y 98 ER. Debido a ello y a partir de entonces, la Asamblea de la UA adoptó una posición más radical afirmando que: «in order to safeguard the constitutional order, stability and integrity of Member States, no charges shall be commenced or continued before any International Court or Tribunal against any serving AU Head of State or Government or anybody acting or entitled to act in such capacity during their term of office» añadiendo en sesiones posteriores una segunda justificación: «the principles deriving from national and International Customary Law by which sitting Heads of State and other senior officials are granted immunities during their tenure in office». Vid. Extraordinary Session of the Assembly of the African Union, October 2013, Addis Ababa (Ethiopia). Doc. Ext/Assembly/AU/Dec.1-2(Oct.2013). Vid. Assembly of the African Union Twenty-Fourth Ordinary Session, January 2015, Addis Ababa (Ethiopia). Doc. Assembly/AU/Dec. 546-568(XXIV). Ante esta posición hemos de mantener su falta de solidez, pues Kenia, al ser Estado Parte en el Estatuto, ha renunciado expresamente y de manera voluntaria a las inmunidades de sus altos cargos ante la CPI. Al mismo tiempo, los principios, la práctica y la opinio iuris analizada en el primer capítulo evidencian la existencia de una costumbre internacional que excepciona la inmunidad de los Jefes de Estado en ejercicio en la relación vis-á-vis ante tribunales internacionales y no lo contrario. Quizás consciente de la limitada solidez de tales argumentos y tras el archivo de los procesos contra Kenyatta y Ruto, en sus últimos informes, la Asamblea de la UA ha vuelto a retomar su posición inicial, defendiendo, sobre la base del artículo 98.1 del Estatuto, la pervivencia de la inmunidad de Al Bashir en tanto que Sudán no es Estado parte de la CPI. Razonamiento que, pese a contar con apoyos entre un sector de la doctrina africana, nos resulta igualmente erróneo. Vid. Assembly of the African Union Twenty-Eighth Ordinary Session, January 2017, Addis Ababa (Ethiopia). Doc. Assembly/AU/Dec.621-641(XXVIII). 
en las elecciones de 2013. Así pues, el primero, quien era de etnia kinkuyu y en las elecciones de 2007 apoyó a Mwai Kibaki, ocupó el cargo de Viceprimer Ministro y Ministro de Finanzas en el Gobierno de coalición entre los años 2009 y 2013. Se presentó a las elecciones presidenciales de marzo de 2013 sobre un discurso basado en sus críticas al papel de la CPI en África y al «neocolonialismo» que le llevó a la victoria. Por su parte William Ruto, de etnia Kalejin quien en las elecciones de 2007 apoyó al opositor Odinga, fue Ministro de Educación, Ciencia y Tecnología en el Gobierno de coalición y a partir de las elecciones de 2013 ocupó el cargo de Vicepresidente.

En ambos casos, la CPI trató la cuestión de la inmunidad en relación al argumento expuesto por las defensas tanto de Kenyatta como de Ruto que alegaban que, al ostentar respectivamente los cargos de Presidente y Vicepresidente, la Corte debería respetar la inmunidad que conllevan sus cargos para que los continuos requerimientos y citaciones no menoscabasen las responsabilidades inherentes al ejercicio de los mismos ${ }^{132}$. $\mathrm{Al}$ refutar este argumento la CPI se refiere al artículo 27 del Estatuto, estableciendo lo siguiente:

«In view of Article 27(1) of the Statute, Mr. Ruto and Mr. Kenyatta are not entitled to special consideration simply because of their position as Head of State and Deputy Head of State of Kenya», [...] «the main aim of

132 Cabe señalar que el 5 de diciembre de 2014 la Fiscalía retiró los cargos contra Uruhu kenyatta por falta de pruebas suficientes para juzgarle por los actos criminales que se le imputaban, señalando que la no cooperación de Kenia había llevado «en gran medida a este resultado». Por su parte, la Sala de Primera Instancia V (B) el 13 de marzo de 2015 archivó definitivamente el caso y dejó sin efecto la orden de comparecencia. No obstante la Sala señala que «in the event of a withdrawal of charges by the Prosecution at this time, the principle of ne bis in idem would not attach, and it would be open to the Prosecution to bring new charges against the accused at a later date, based on the same or similar factual circumstances, should it obtain sufficient evidence to support such a course of action». Vid. CPI, «Decision on the withdrawal of charges against Mr. Kenyatta», 13 de marzo de 2015, n. ${ }^{\circ}$ ICC-01/09-02/11-1005, párr. 9.

Respecto de William Ruto, el 12 de febrero de 2016 la Sala de Apelaciones revocó el fallo de la Sala de Primera Instancia que admitió como prueba «el uso de los testimonios iniciales de los testigos, que posteriormente habían cambiado su declaración o se negaron a cooperar, sobre la base de la regla 68 modificada de las Reglas de Procedimiento y Prueba. La Sala de Apelaciones mantuvo que, dado que esta regla se había modificado después del inicio del procedimiento, se había aplicado de forma retroactiva y en detrimento del acusado porque supondría admitir pruebas incriminatorias en su contra». El motivo de fondo se encuentra en que los testigos iniciales han dejado de cooperar debido a sobornos o por miedo a represalias. Finalmente, el 5 de abril de 2016, la Sala de Primera Instancia V (A) decidió dar por terminado el Caso contra Ruto y Sang por no existir pruebas suficientes contra los sospechosos. Vid. Federación Internacional de Derechos Humanos (FIDH), Fin del procedimiento de Ruto y Sang en la CPI. Comunicado Movimiento Mundial de DDHH, marzo de 2016, p. 2 y ss. 
Article 27(1) is to align the ICC Statute with the contemporary norm of international law according to which public officials are no longer entitled to immunity for violation of international criminal law» ${ }^{133}$.

Dicho esto, la Corte ahonda en la naturaleza del precepto, señalando que éste recoge una excepción de Derecho consuetudinario ya presente, entre otros, en los Principios de Nuremberg, en los Estatutos de los Tribunales Penales para la ex Yugoslavia y Ruanda y en el Estatuto del Tribunal Especial para Sierra Leona ${ }^{134}$. La CPI, por ende, parece hacer referencia a la posición ya mantenida en las Decisiones de diciembre de 2011 dirigidas a Malawi y Chad en relación al caso $\mathrm{Al}$ Bashir. Como ya hemos argumentado en líneas anteriores, nos parece acertado este razonamiento, no obstante, se hubiera agradecido una mención expresa a tales decisiones con objeto de, ante sus continuos vaivenes, asentar una jurisprudencia sólida y coherente al respecto ${ }^{135}$.

\subsection{Caso Gbagbo}

El vencedor de las elecciones presidenciales que tuvieron lugar en Costa de Marfil el 28 de noviembre de 2010 fue Alassane Ouattara, quedando en segunda posición Laurent Gbagbo, el que hasta entonces y desde el 2000 había sido Presidente del país.

Este último no reconoció los resultados y se mantuvo en el poder apoyándose en altos cargos del ejército. Al mismo tiempo Ouattara empezó a ejercer su cargo de presidente en las dependencias del Golf Hotel situado en la ciudad marfileña de Abidjan. Esta confrontación se tradujo en altercados violentos entre los que apoyaban a uno y a otro bando, altercados que fueron

133 ICC, «Decision on Defence Request for Conditional Excusai from Continuous Presence at Trial», Case of the Prosecutor v. Ruto, 18 June 2013, n. ${ }^{\circ}$ ICC-01/09-01/11, párrs. 23 y 66.

${ }^{134}$ Ibid., párrs. 66-70.

135 A diferencia del caso Al Bashir, no ha sido necesario que la CPI se pronuncie sobre el segundo plano que venimos planteando, pues tanto Kenyatta como Ruto han comparecido voluntariamente ante la misma. No obstante, de no haberse producido tal comparecencia voluntaria y haber tenido la CPI que emitir una orden de arresto, este segundo plano no actuaría de manera tan controvertida como en el caso Al Bashir, pues, como ha sido señalado, el artículo 98.1 no opera en la relación triangular entre la Corte, Estado parte requerido y tercer Estado parte (en este caso Kenia), en tanto que, al ratificar el Estatuto de Roma, se ha renunciado expresamente en virtud del artículo 27 a toda inmunidad, tanto personal como funcional, que los agentes estatales pudieran tener ante la Corte. 
alentados por Gbagbo, quien orquestó ataques sistemáticos y generalizados contra los seguidores de Ouattara.

Por su parte, tanto el Consejo de Seguridad ${ }^{136}$ como la Unión Africana exigieron a Gbagbo acatar el resultado de las elecciones de 2010 y acabar con la violencia contra la población civil. Finalmente las fuerzas de la ONU en Costa de Marfil (ONUCI), apoyadas por el ejército francés, lograron poner fin a los ataques dirigidos contra los leales a Alassane Ouattara, quien el 6 de mayo de 2011 ocupó oficialmente el cargo de Presidente ${ }^{137}$.

Antes de detenernos en el caso Gbagbo cabe mencionar que, si bien, en el periodo en el que tuvo lugar la violencia postelectoral Costa de Marfil no era Estado parte en el Estatuto de Roma, el 18 de abril de 2003 el Gobierno marfileño presentó, de conformidad con el artículo 12.3 del Estatuto, una declaración ante la Secretaría de la Corte en la que aceptaba la competencia de la CPI respecto de los crímenes cometidos en su territorio a partir del 19 de septiembre de $2002^{138}$. Dicha declaración fue confirmada por el Presidente Outtara en noviembre de 2010 y en mayo de 2011. Dos años más tarde, concretamente en febrero de Costa de Marfil ratificó el Estatuto de Roma y pasó a ser Estado parte del mismo.

Volviendo al tema que nos ocupa, el 3 de octubre de 2011, la Sala de Cuestiones Preliminares III dictó una decisión de conformidad con el artículo 15 del Estatuto autorizando una investigación sobre la situación en Costa de Marfil ${ }^{139}$. Por su parte, en octubre de 2011, el Fiscal presentó una solicitud de conformidad con el artículo 58 del Estatuto en la que pedía que se dictara una orden de detención contra Laurent Gbagbo por la presunta comisión de cuatro crímenes de lesa humanidad en el periodo de violencia postelectoral que tuvo lugar entre 2010 y 2011, orden que fue emitida en noviembre de

136 Resolución 1975 (2011) del Consejo de Seguridad, de 30 de marzo de 2011. Disponible en: http:// www.refworld.org/cgi-bin/texis/vtx/rwmain/opendocpdf.pdf? reldoc=y\&docid=4d9ac5742 [consultado: 13/06/2017].

137 Birchall, J., «The Trial of Laurent Gbagbo and Charles Blé Goudé at the ICC», Open Society Fustice Initiative Briefing Paper, enero de 2016, p. 4.

138 De esta forma, Costa de Marfil ha sido el primer Estado no parte en el Estatuto de Roma que ha consentido de conformidad con el artículo 12.3 que la Corte ejerza su competencia respecto a los crímenes cometidos en su territorio. Vid. ICC, «Declaration Accepting the Jurisdiction of the International Criminal Court by Republic of Côte d'Ivoire», 18 April 2003. Disponible en: https://www.icc-cpi.int/NR/rdonlyres/57B00915-8FDF-4532-9BDE-8AF338E3E364/279844/ ICDEENG7.pdf [consultado: 26/06/2017].

${ }^{139}$ ICC, «Decision Pursuant to Article 15 of the Rome Statute on the Authorisation of an Investigation into the Situation in the Republic of Côte d'Ivoire», 3 October 2011, n. ${ }^{\circ}$ ICC-02/11-14. 
$2011^{140}$. El Gobierno de Costa de Marfil cooperó con la Corte en la detención y entrega del Expresidente, posibilitando que el juicio, que aún sigue abierto ante la Sala de Primera Instancia I, comenzase el 28 de enero de 2016. De esta forma, Laurent Gbagbo pasó a ser el primer expresidente de un Estado que está siendo juzgado por la Corte.

Hemos traído el caso Gbagbo para ratificar lo mantenido en el primer capítulo de esta obra: atendiendo al Derecho internacional vigente no es controvertido afirmar la improcedencia del cargo oficial ante tribunales internacionales por la comisión de los crímenes más atroces contra la humanidad una vez que el agente o funcionario estatal cese del cargo. Planteamiento secundado por la UA en el caso Gbagbo ${ }^{141}$. No obstante, aunque hay que reconocer que la defensa no ha basado su estrategia sobre el principio de inmunidad, no habría estado de más que la Corte se hubiera pronunciado expresamente sobre dicha cuestión con objeto de evidenciar uno de los (limitados) aspectos no controvertidos respecto de la inmunidad de jurisdicción penal de los Jefes de Estado ${ }^{142}$.

\section{Conclusiones}

I. Ante tribunales nacionales extranjeros los Jefes de Estado gozan tanto de inmunidad ratio personae como de inmunidad ratio materiae con independencia del delito cometido, si bien respecto a esta última, junto a la opinión de distintos autores, empieza a evidenciarse una incipiente práctica judicial y nor-

\footnotetext{
140 Para un análisis detallado del desarrollo del proceso vid. CPI, «Trial of Laurent Gbagbo opens at International Criminal Court», 26 de febrero de 2016. Disponible en: https://www.icc-cpi.int/ pages/item.asp $x$ ?name $=P R 1184$ [consultado: 16/07/2017].

${ }^{141} \mathrm{Vid}$. ILC, «Fifth report...», op. cit., párrs. 166 y 188.

142 Cabe añadir que la CPI decidió unir los casos Gbagbo y Blé Goudé el 11 de marzo de 2015, siéndole imputados a éste último, quien fue Ministro de Juventud de Gbagbo, los mimos cargos que al Expresidente. Asimismo, la Sala de Cuestiones Preliminares III emitió a petición de la Fiscalía una orden de arresto en febrero de 2012 contra la ex Primera Dama de Costa de Marfil, Simone Gbagbo, por la presunta comisión de cuatro crímenes de lesa humanidad. Sin embargo, las autoridades marfileñas se han negado a cooperar en su entrega alegando que ya había sido enjuiciada ante tribunales internos, los cuales en marzo de 2015 la condenaron a veinte años de prisión. No obstante, en mayo de 2015 la Corte rechazó este argumento y confirmó que el caso contra Simone Gbagbo permanece activo ante la CPI. Vid. ICC, «Judgment on the appeal of Côte d'Ivoire against the decision of Pre-Trial Chamber I of 11 December 2014 entitled «Decision on Côte d'Ivoire's challenge to the admissibility of the case against Simone Gbagbo», 27 May 2015, Doc. ICC-02/11-01/12-75.
} 
mativa en contrario cuando se trata de crímenes internacionales. Por su parte, ante tribunales internacionales, desde el final de la Segunda Guerra Mundial se viene consolidando una excepción al principio de inmunidad de jurisdicción penal de los Jefes de Estado cuando son investigados y juzgados por la comisión de crímenes internacionales que alcanza no solo a la inmunidad funcional, como mantiene la UA, sino también a la personal.

II. Centrándonos en el Estatuto de Roma, instrumento constitutivo de la Corte Penal Internacional, la lectura de su artículo 27 ha de hacerse desde distintas perspectivas. Así pues, por una parte consagra el principio consuetudinario de improcedencia del cargo oficial ante tribunales internacionales, al que nos hemos referido, pero, al mismo tiempo, en virtud del citado precepto los Estados parte renuncian expresamente a cualquier tipo de inmunidad ratio materiae y ratio personae que sus agentes pudieran ostentar cuando otro Estado, en cumplimiento del deber de cooperar con la CPI, detenga y arreste al agente en cuestión para permitir que la Corte ejerza su competencia.

Por su parte, la finalidad del artículo 98.1 es evitar el posible conflicto de deberes que podría producirse cuando el cumplimiento de la obligación de cooperar con la Corte conduzca a un Estado parte a no respetar las inmunidades de los agentes de Estados no parte reconocidas por el Derecho internacional. Así pues, la lectura conjunta del artículo 27 y 98.1 solo opera cuando el agente lo es de un Estado no parte en el ER, debiéndose diferenciar a este respecto entre dos niveles: por un lado, la relación vis-à-vis entre la Corte y el Estado del agente estatal, que opera desde un plano vertical y, por otro, la cooperación y asistencia judicial de los Estados con la CPI, que origina una relación triangular entre la Corte, el Estado parte requerido y el tercer Estado no parte del agente. De forma tal que, mientras del primero, la exclusión de la inmunidad juega de forma absoluta -en virtud del artículo 27, que, a este respecto, es a su vez una norma declarativa de derecho consuetudinario-, en el segundo subsisten algunas manifestaciones de la inmunidad en su dimensión internacional -que son previstas por el artículo 98.1-, pues, al no recepcionar en relación a éste segundo plano una norma consuetudinaria, dicho precepto no puede crear obligaciones para un Estado no parte sin su consentimiento.

Por el contrario, cuando el agente lo es de un Estados parte el artículo 98.1 no opera, pues los Estados que han ratificado el ER han renunciado expresamente en virtud del artículo 27 a toda inmunidad, tanto personal como funcional, que sus agentes pudieran tener ante la Corte, ya sea en el plano vertical como horizontal. 
III. A la complejidad de la articulación de tales preceptos ha de añadirse que la CPI no ha establecido una línea jurisprudencial uniforme. Centrándonos en el Caso Al Bashir, donde la Corte ha tratado de manera más detallada la cuestión de la inmunidad, en la primera orden de arresto emitida el 4 de marzo de 2009 el Tribunal sólo trató el plano referido a la relación vis-á-vis entre la Corte con el Estado de Sudán, defendiendo la excepción a la inmunidad sobre la base exclusiva del Estatuto de Roma. Por su parte, en la decisión de 12 de diciembre de 2011 la Corte, respecto del plano vertical, con acierto sostuvo la improcedencia del cargo oficial ante tribunales internacionales sobre la base del Derecho internacional consuetudinario, pero entendió erróneamente que éste alcanzaba a la relación triangular Corte, Estado requerido y tercer Estado no parte. Finalmente, en la decisión de 9 abril de 2014, la CPI vuelve a errar al pronunciarse sobre la relación vis-á-vis con el Estado de Sudán, pues retoma la postura ya mantenida en su primer pronunciamiento, arguyendo respecto del segundo plano que en cumplimiento de la expresión «cooperación plena» utilizada en la Resolución 1593 (2005) CSNU se ha procedido implícitamente a retirar las inmunidades del Presidente sudanés y, por ende, los Estados no pueden alegar ningún conflicto de obligaciones en su deber de cooperar con la Corte. Posición, ésta última, mantenida hasta el momento en sucesivos pronunciamientos.

Lejos de desenredar tal embrollo, en el caso Gadafi la Corte sólo se ha referido al primer plano planteado, haciendo una remisión abierta al Caso $\mathrm{Al}$ Bashir sin especificar, a este respecto, a cuál de sus diferentes pronunciamientos atenernos. De igual manera, en el caso Kenyatta tan solo se ha detenido en la relación vis-á-vis de la Corte con el Estado de Kenia, aunque, esta vez sí, señalando acertadamente, como hiciera en el caso $\mathrm{Al}$ Bashir en su pronunciamiento de 12 de diciembre de 2011, que, a este respecto, el artículo 27 es una norma declarativa de Derecho internacional consuetudinario.

Por ende, hasta el momento, ninguno de los pronunciamientos de la CPI ha tratado conjuntamente ambos planos de manera acertada. Debiéndose añadir a lo hasta ahora expuesto que, si bien, coincidimos con la Corte en su decisión de 9 abril de 2014 respecto a la relación triangular entre la Corte, el Estado parte requerido y el tercer Estado no parte del agente, nuestro recorrido argumental difiere del adoptado por la CPI. Pues mantenemos que es la propia remisión del CSNU -y no el lenguaje utilizado en la misma- la que conlleva -a todos los efectos- que el Estado de Sudán se sitúe en una posición análoga a la de un Estado parte, y, por consiguiente, le sea aplicable el artículo 27 del Estatuto como a cualquier otro Estado que lo hubiera ratificado. De ahí 
que no rijan las inmunidades que han de ser respetadas de conformidad con el art. 98.1.

IV. Si la CPI hubiera establecido una línea jurisprudencial coherente, los planteamientos de la Unión Africana respecto a los artículos 27 y 98 ER podrían haber sido fácilmente rebatidos. Sin embargo, con sus vaivenes y sin ni siquiera hacer mención a la razón de tales cambios argumentales, la Corte solo ha generado más confusión a la ya de por si intrincada materia. En todo caso, de mantenerse el carácter vinculante de las decisiones adoptadas por la Asamblea de la UA, en el asunto Al Bashir, el único caso abierto en el que existen actualmente posiciones contrapuestas, no se produce una confrontación entre la CPI y la UA, sino entre las decisiones adoptada por ésta y la Resolución 1593(2005) del Consejo de Seguridad, debiendo dicha contraposición ser solucionada atendiendo a los artículos 25 y 103 de la Carta de la ONU.

V. Finalmente, con independencia de la línea jurisprudencial mantenida por la Corte, ésta ha venido subrayando acertadamente, como se deriva de la propia redacción del artículo 98.1 y de la Regla 195.1 de las Reglas de Procedimiento y Prueba, que es la propia CPI la que debe valorar si una petición de cooperación puede situar a un Estado parte ante un conflicto de obligaciones. Por ende, la decisión unilateral de los Estados parte de no cumplir con los requerimientos de la Corte infringe el Estatuto de Roma. 

NOTAS 
